\title{
TRADE COSTS, MARKET ACCESS AND ECONOMIC GEOGRAPHY: WHY THE EMPIRICAL SPECIFICATION OF TRADE COSTS MATTERS
}

\author{
MAARTEN BOSKER \\ HARRY GARRETSEN
}

CESIFO WORKING PAPER NO. 2071

CATEgory 7: Trade Policy

August 2007

\footnotetext{
An electronic version of the paper may be downloaded

- from the SSRN website: Www.SSRN.com

- from the RePEc website: $\quad$ www.RePEc.org

- from the CESifo website: www.CESifo-group.org/wp
} 


\title{
TRADE COSTS, MARKET ACCESS AND ECONOMIC GEOGRAPHY: WHY THE EMPIRICAL SPECIFICATION OF TRADE COSTS MATTERS
}

\begin{abstract}
Trade costs are a crucial in new economic geography (NEG) models. The unavailability of actual trade costs data requires the approximation of trade costs. Most NEG studies do not deal with the ramifications of the particular trade costs specification used. This paper shows that the specification of trade costs matters. Estimations of a NEG wage equation for a sample of 80 countries show how the relevance of the key NEG variable, market access, depends upon the trade costs specification. Our conclusion is that NEG needs to (re-)examine the sensitivity of its empirical findings to the handling of trade costs.
\end{abstract}

JEL Code: R12, F1, F12.

Maarten Bosker

Utrecht School of Economics

Utrecht University

Janskerkhof 12

3512 BL Utrecht

The Netherlands

M.Bosker@econ.uu.nl
Harry Garretsen

Utrecht School of Economics

Utrecht University

Janskerkhof 12

3512 BL Utrecht

The Netherlands

H.Garretsen@econ.uu.nl

This version: July 2007, comments welcome.

The authors would like to thank Joppe de Ree and Marc Schramm for useful comments and suggestions. Please address correspondence to Maarten Bosker. 


\section{INTRODUCTION}

Trade costs are a key element of new economic geography models in determining the spatial distribution of economic activity (see e.g. Krugman, 1991; Venables, 1996 and Puga, 1999): without trade costs there is no role for geography in NEG models. It is therefore not surprising that trade costs are also an important ingredient of empirical studies in NEG (see e.g. Redding and Venables, 2004; Hanson, 2005 or Head and Mayer, 2004). They are a vital ingredient of a region's or country's (real) market potential, that measures the ease of access to other markets (Redding and Venables, 2004; Head and Mayer, 2006). In the empirical trade literature at large, trade costs are also a main determinant of the amount of trade between countries (see e.g. Limao and Venables, 2001; Anderson and van Wincoop, 2004).

The empirical specification of trade costs is, however, far from straightforward ${ }^{1}$. Problems with the measurement of trade costs arise because trade costs between any pair of countries are very hard to quantify. Trade costs most likely consist of various subcomponents that potentially interact, overlap and/or supplement each other. Obvious candidates are transport costs, tariffs and non-tariff barriers (NTBs), but also less tangible costs arising from cross-border trade due to e.g. institutional and language differences have been incorporated in previous studies (Limao and Venables, 2001). An additional difficulty arises with what is arguably the most obvious measure of trade costs, transport costs. Accurate transport cost data between country pairs are very difficult to obtain and even completely unavailable when considering transport costs between regions ${ }^{2}$. In principle, between-country transport costs can be inferred from cif/fob ratios. The IMF provides for instance extensive trade data on the basis of which these cif/fob ratios can be calculated, see e.g. Limao and Venables (2001) and Baier and Bergstrand (2001). However as put forward by Hummels (1999, p.26) these data "suffer from severe quality problems and broad inferences on these numbers may be unwarranted"3.

\footnotetext{
${ }^{1}$ The specification of trade costs may also be not that straightforward from a theoretical point of view, see McCann (2005) and Fingleton and McCann (2007).

${ }^{2}$ Where actual transport cost data are used in the empirical literature the coverage in terms of the number of country pairs is very limited (e.g. costs of shipping a standard 40-foot container from Baltimore (USA) to 64 different countries in Limao and Venables, 2001) or only the evolution of average (by world-region) transport costs over time is available (e.g. Norwegian and German shipping indices and air cargo rates in Hummels, 1999).

${ }^{3}$ Hummels infers transport costs by making use of more accurate data, but these data are only available for very few countries.
} 
The problems of measuring trade costs that beset the empirical trade literature also apply to empirical studies into the relevance of NEG since any attempt to shed light on the empirical relevance of NEG calls for the availability of bilateral trade costs between a sufficiently large number of countries or regions (e.g. Redding and Venables, 2004; Hanson, 2005; Brakman et al., 2006; Knaap, 2006). Given the unavailability of a direct measurement of bilateral trade costs, all NEG studies turn to the indirect measurement of trade costs. In doing so, they closely follow the empirical trade literature (see Anderson and van Wincoop, 2004 for a very good survey of the latter) and assume a so-called trade cost function. This trade cost function aims to proxy the unobservable trade costs by combining information on observable trade cost proxies such as distance, common language, tariffs, adjacency, etc with assumptions about the unobservable trade cost component. The assumptions made about this trade cost function, e.g. functional form, parameter hetero- or homogeneity across country pairs, which observable cost proxies to include or how to estimate each cost proxy's effect, all potentially have a (crucial) effect on the results of any empirical study.

In the empirical NEG literature, the measurement of trade costs is only a means to an end, and as a result the relevance of the preferred trade costs specification for the conclusions with respect to the NEG hypotheses under consideration is typically ignored. Virtually all studies just pick a trade cost specification and do not (or only marginally) address the question as to the sensitivity of their results to their chosen approximation of trade costs. This paper aims to overcome this lack of attention by systematically estimating and comparing trade cost functions that have been used in the empirical NEG literature. We use various trade cost functions to estimate a standard NEG wage equation for 80 countries and look into the importance of the trade costs specification for the relevance of market access, the central NEG variable when it comes to inter-regional spatial interdependencies, as a determinant in the difference in gdp per capita between countries. It turns out that the way trade costs are proxied has substantial effects when it comes to the conclusions about the relevance of market access. Trade costs matter not only in terms of the size (and sometimes also the significance) of the market access effect, but also in terms of the spatial reach of economic shocks. The upshot of our paper is that the empirical specification of trade costs really matters for the conclusions reached with respect to the empirical relevance of NEG models. 
The paper is organized as follows. In the next section we first introduce the basic NEG model with a focus on the equilibrium wage equation and the role of trade costs. Next we discuss the two estimation strategies that have been used in the literature to estimate the wage equation, both of which require the specification of a trade cost function. Section 3 discusses the main conceptual difficulties involved in the approximation of trade costs by specifying a trade cost function. Given these difficulties, section 4 introduces a third way to approximate trade costs, which does not require a trade cost function but instead infers bilateral trade costs directly from bilateral trade data. Section 5 introduces our data set. In section 6 we present our estimation results for the NEG wage equation, hereby focussing in detail on the impact of the choice of trade cost approximation used and estimation strategies on the key explanatory NEG variable, market access. It turns out that the relevance of market access, or in other words of spatial interdependencies between countries, depends strongly on the choice of trade cost approximation. Section 7 concludes.

\section{TRADE COSTS AND THE WAGE EQUATION IN NEG}

The need to have a measure of trade costs when doing empirical work on NEG models immediately becomes clear when discussing the basic NEG model on which the empirical studies are based (e.g. Redding and Venables, 2004; Knaap, 2006; Brakman et al., 2006; Hanson, 2005). This section first develops the theory behind the widely used wage equation that serves as the vehicle for our empirical research too (e.g. Krugman, 1991; Venables, 1996 and Puga, 1999). Our exposition is largely based on the seminal paper by Redding and Venables (2004) ${ }^{4}$. In the second part of this section, we move from theory to empirics by introducing the two different estimation strategies that have to date been used to estimate the parameters of the NEG wage equation (see Head and Mayer, 2004), focussin explicitly on the specification of trade costs.

\footnotetext{
${ }^{4}$ See their paper, or Puga (1999) and Fujita et al. (1999) ch.14, for more details on these types of models.
} 


\subsection{The basic NEG model}

Assume the world consists of $i=1, \ldots, R$ countries, each home to an agricultural and a manufacturing sector ${ }^{5}$. In the manufacturing sector; firms operate under internal increasing returns to scale, represented by a fixed input requirement $c_{i} F$ and a marginal input requirement $c_{i}$. Each firm produces a different variety of the same good under monopolistic competition using the same Cobb-Douglas technology combining three different inputs. The first is an internationally immobile primary factor (labour), with price $w_{i}$ and input share $\beta$, the second is an internationally mobile primary factor with price $v_{i}$ and input share $\gamma$ and the third is a composite intermediate good with price $G_{i}$ and input share $\alpha$, where $\alpha+\gamma+\beta=1$.

Manufacturing firms sell their variety to all countries and this involves shipping the goods to foreign markets. This is where the trade costs come in, these are assumed to be of the iceberg-kind and the same for each variety produced, i.e. in order to deliver a quantity $x_{i j}(z)$ of variety $z$ produced in country $i$ to country $j, x_{i j}(z) T_{i j}$ has to be shipped from country $i$. A proportion $\left(T_{i j}-1\right)$ of output 'is paid' as trade costs (note that $T_{i j}=1$ if trade is costless). Note that this relatively simple iceberg specification (introduced mainly for ease of modelling purposes) does not specify in any way what trade costs are composed of. It is precisely the need to specify $T_{i j}$ more explicitly in empirical research, see below, that motivated our paper. Taking these shipping costs into account gives the following profit function for each firm in country $i$,

$$
\pi_{i}=\sum_{j}^{R} p_{i j}(z) x_{i j}(z) / T_{i j}-G_{i}^{\alpha} w_{i}^{\beta} v_{i}^{\gamma} c_{i}\left[F+\sum_{j}^{R} x_{i j}(z)\right]
$$

where $p_{i j}(z)$ is the price of a variety produced in country $i$.

Turning to the demand side, each firm's product is both a final (consumption) and an intermediate (production) good. It is assumed that these products enter both utility and production in the form of a CES-aggregator with $\sigma$ the elasticity of substitution between each pair of product varieties. Given this CES-assumption about both consumption and intermediate production, it follows directly that in equilibrium all product varieties produced in country $i$ are demanded by country $j$ in the same quantity (for this reason varieties are no longer explicitly indexed by $(z)$ ). Denoting country $j$ 's expenditure on manufacturing goods (coming from both firms and

\footnotetext{
${ }^{5}$ In the theoretical exposition, countries are used as the geographical unit of interest. Instead of countries we could have taken any other geographical level of aggregation, e.g. regions, cities, districts, counties, or provinces.
} 
consumers) as $E_{j}$, country $j$ 's demand for each product variety produced in country $i$ can be shown to be (following utility maximization and cost minimization on behalf of consumers and producers respectively),

$$
x_{i j}=p_{i j}^{-\sigma} E_{j} G_{j}^{(\sigma-1)}
$$

where $G_{j}$ is the price index for manufacturing varieties that follows from the assumed CES-structure of both consumer and producer demand for manufacturing varieties. It is defined over the prices, $p_{i j}$, of all goods produced in country $i=1, \ldots, R$ and sold in country $j$,

$$
G_{j}=\left[\sum_{i}^{R} n_{i} p_{i j}^{1-\sigma}\right]^{1 /(1-\sigma)}
$$

Maximization of profits (1) combined with demand as specified in (2) gives the wellknown result in the NEG literature that firms set the same f.o.b. price depending only on the location of production, $p_{i}$ (so that price differences between countries of a good produced in country $i$ only arise from differences in trade costs, i.e. $p_{i j}=p_{i} T_{i j}$ ), where $p_{i}$ is a constant markup over marginal costs:

$$
p_{i}=G_{i}^{\alpha} w_{i}^{\beta} v_{i}^{\gamma} c_{i} \sigma /(\sigma-1)
$$

Next, free entry and exit drive (maximized) profits to zero, which pinpoints equilibrium output per firm at $\bar{x}=(\sigma-1) F$. Finally combining this equilibrium output with equilibrium price (4) and equilibrium demand (2), and noting that in equilibrium the price of the internationally mobile primary factor of production will be the same across countries ( $v_{i}=v$ for all $i$ ), gives the equilibrium wage of the composite factor of immobile production, i.e. labour,

$$
w_{i}=A G_{i}^{-\alpha / \beta} c_{i}^{-1 / \beta}\left(\sum_{j}^{R} E_{j} G_{j}^{(\sigma-1)} T_{i j}^{(1-\sigma)}\right)^{\frac{1}{\beta \sigma}}
$$

where $A=v^{-\gamma / \beta}\left[(\sigma-1)^{\frac{\sigma-1}{\sigma}} F^{-1 / \sigma} / \sigma\right]^{1 / \beta}$ is a constant.

Equation (5) is the wage equation that is at the heart of those empirical studies in NEG that try to establish whether, as equation (5) indicates, there is a spatial wage structure with wages being higher in economic centers (e.g. Brakman et al., 2006; Knaap, 2006; Redding and Venables, 2004; Mion, 2004 and Hanson, 2005). More precisely, the wage equation (5) says that the wage level a country is able to pay its manufacturing workers is a function of that country's technology, $c_{i}$, the price index 
of manufactures in that country, $G_{i}$, and so called real market access, the sum of trade cost weighted market capacities ${ }^{6}$.

Note that trade costs play a crucial role in (5), most visibly in the real market access term. It also plays a role in the price index of manufactures (3), i.e. using $p_{i j}=$ $p_{i} T_{i j}$ :

$$
G_{j}=\left[\sum_{i}^{R} n_{i} p_{i}^{1-\sigma} T_{i j}^{1-\sigma}\right]^{1 /(1-\sigma)}
$$

Wages are relatively higher in countries that have easier access to consumer markets in other countries when selling their products and that have easier access to products produced in other countries (producer markets). The lower trade costs, the easier access to both producer and consumer markets abroad, the higher wages firms can offer to workers. Trade costs are thus of vital importance in determining the spatial distribution of income.

We now turn to the discussion of the two different ways by which the wage equation has been estimated in the literature so far. Hereby particularly emphasizing the way in which trade costs are dealt with.

\subsection{Estimating the wage equation}

Taking logs on both sides of (5) gives the following non-linear equation that can be estimated:

$$
\ln w_{i}=\alpha_{1}+\alpha_{2} \ln G_{i}+\alpha_{3} \ln \left(\sum_{j}^{R} E_{j} G_{j}^{(\sigma-1)} T_{i j}^{(1-\sigma)}\right)+\eta_{i}
$$

where $\eta_{i}$ captures the technological differences, $c_{i}$, between countries that typically consists of both variables that are correlated (modelled by including e.g. measures of physical geography or institutional quality) and/or variables that are uncorrelated (modeled by an i.i.d. lognormal disturbance term) with market and supplier access. The $\alpha$ 's are the estimated parameters from which in principle the structural NEG parameters can be inferred. There are basically two different ways in which wage equation (7) has been estimated in the empirical NEG literature.

\footnotetext{
${ }^{6}$ The actual wage equation estimated may differ slightly from the one presented here in each particular empirical study, but the basic idea behind it is always the same, i.e. with wage depending on real market access and the price index of manufactures, which to a very large extent depend on the level of trade costs between a country (or region) and all other countries (regions).
} 


\subsubsection{Direct non-linear estimation of the wage equation}

The first empirical strategy to estimate the wage equation was introduced by Hanson (2005) and can be discussed rather briefly. It involves direct non-linear estimation of the wage equation (7). Authors that have subsequently followed this direct non-linear estimation strategy include Brakman et al. (2004; 2006), and Mion (2004) ${ }^{7}$.

To deal with the unavailability of directly measurable trade costs, all papers in the "Hanson"-tradition assume a trade cost function to deal with the need to specify $T_{i j}$ for empirical research (see the next section) ${ }^{8}$. What is important here is that this trade cost function is subsequently directly substituted for $T_{i j}$ in (7). Its parameters are jointly estimated along with the parameters of the wage equation. This is rather different from the second estimation strategy.

\subsubsection{Two-step linear estimation of the wage equation making use of trade data}

The second strategy comes from the work by Redding and Venables (2004) and involves a two-step procedure where in the first step the information contained in (international) trade data is used to provide estimates of so-called market and supplier capacity and bilateral trade costs that are subsequently used in the second step to estimate the parameters of the wage equation. Other papers using this strategy include inter alia Knaap (2006), Breinlich (2006), Head and Mayer (2006) and Hering and Poncet (2006).

Instead of directly estimating (7), this estimation strategy makes use of the following definition of bilateral trade flows between countries that follows directly from aggregating the demand from consumers in country $j$ for a good produced in country $i$ (2) over all firms producing in country $i$ :

$$
E X_{i j}=n_{i} p_{i} x_{i j}=n_{i} p_{i}^{1-\sigma} T_{i j}^{1-\sigma} E_{j} G_{j}^{\sigma-1}
$$

\footnotetext{
${ }^{7}$ The first version of this paper was already available as an NBER working paper (nr.6429) in February 1998. This explains why others have used his methodology and have published their work earlier than Hanson himself.

${ }^{8}$ Besides information on trade costs, $T_{i j}$, also the data on the price index, $G_{i}$, is unavailable at the regional level. Very briefly, the problems with the lack of data on regional price indices are solved by either using, besides the wage equation, other (long run) equilibrium conditions ${ }^{8}$ (Hanson, 2005; Brakman et al., 2004 and Mion, 2006) or by assuming away the use of intermediates in manufacturing production $(\alpha=0)$ and approximating each region's price index by the average wage level in the economic centers that are closest to that region (Hanson, 2005 Brakman et al., 2006), see also Head and Mayer, 2004, p. 2624.
} 
Equation (8) says that exports from country $i$ to country $j$ depend on the 'supply capacity', $n_{i} p_{i}^{1-\sigma}$, of the exporting country that is the product of the number of firms and their price competitiveness, the 'market capacity', $E_{j} G_{j}^{\sigma-1}$ of the importing country and the magnitude of bilateral trade costs $T_{i j}$ between the two countries. Taking logs on both sides of (8) and replacing market and supply capacity by an importer and exporter dummy respectively, i.e. $s_{i}=n_{i} p_{i}^{1-\sigma}$ and $m_{j}=E_{j} G_{j}^{\sigma-1}$, results in the following equation that is estimated:

$$
\ln E X_{i j}=\ln s_{i}+(1-\sigma) \ln T_{i j}+\ln m_{j}+\varepsilon_{i j}
$$

where $\varepsilon_{i j}$ is an i.i.d. lognormal disturbance term.

In the second step, the estimated country specific importer and exporter dummies and the predicted value of bilateral trade costs that result from the estimation of (9) are then used to construct so-called market and supplier access. These are defined as follows respectively, see Redding and Venables (2004, pp. 61-62) for more details:

$$
\begin{aligned}
& M A_{i}=\sum_{j}^{R} E_{j} G_{j}^{\sigma-1} T_{i j}^{1-\sigma}=\sum_{j}^{R} m_{j} T_{i j}^{1-\sigma} \\
& S A_{j}=\sum_{i}^{R} n_{i} p_{i}^{1-\sigma} T_{i j}^{1-\sigma}=\sum_{i}^{R} s_{i} T_{i j}^{1-\sigma}
\end{aligned}
$$

The predicted values of market and supplier access are subsequently used to estimate the wage equation, i.e. rewriting (5), using (6) and (10) and taking logs on both sides gives:

$$
\ln w_{i}=\alpha_{1}+a_{2} \ln S A_{i}+\alpha_{3} \ln M A_{i}+\eta_{i}
$$

where $\eta_{i}, \alpha_{1}$ and $\alpha_{3}$ are as specified in (7) and $a_{2}$ captures a somewhat different combination of structural parameters than $\alpha_{2}$ in (7).

The problem of the unavailability of a direct measurement of trade costs when using this estimation strategy enters in the first step. All papers solve this problem by assuming a trade cost function (see next section). The parameters of this trade cost function are jointly estimated with the importer and exporter dummies and subsequently used in the construction of the predicted values of market and supplier access. As opposed to the direct estimation of the wage equation, the parameters of the distance function are thus not jointly estimated with the parameters of the NEG wage equation. 
The motivation for Redding and Venables (2004) to use this 2-step strategy, is that "this approach has the advantage of capturing relevant country characteristics that are not directly observable but are nevertheless revealed through trade performance" (Redding and Venables, 2004, p. 75). Still, they have to assume an empirical specification for the trade cost function, and moreover the country dummies may be capturing 'too much' relevant country characteristics (see section 3 for more detail). In section 4 we, following Head and Ries (2001), will take the idea that actual trade data can be used as a foundation for market and supplier access in the wage equation one step further by letting trade data determine the total trade costs thereby circumventing the need to explicitly specify the trade function $T_{i j}$. But before doing so, we first discuss the main important assumptions, often implicitly made, that are involved when one approximates $T_{i j}$ by making use of a trade cost function.

\section{THE TRADE COST FUNCTION}

All papers using either the direct or two-step estimation strategy deal with the unavailability of a direct measure of trade costs by specifying a trade cost function. In its most general form the trade cost function is:

$$
T_{i j}=f\left(X_{i j}, X_{j}, X_{i}, v_{i j}\right)
$$

The trade costs involved in shipping goods from country $i$ to country $j$ are a function $f$ of cost factors that are specific to the importer or the exporter ( $X_{j}$ and $X_{i}$ respectively), such as infrastructure, institutional setup or geographical features of a country (access to the sea, mountainness), bilateral cost factors related to the actual journey from $j$ to $i, X_{i j}$, such as transport costs, tariffs, sharing a common border, language barriers, membership of a free trade union, etc, and unobservable factors, $v_{i j}$. Given the afore mentioned unavailability of transport cost data between a sufficient number of countries, these are in turn also proxied by most notably bilateral distance, but sometimes also actual travel times or population weighted distance are used.

The trade cost function that is used in estimating the wage equation in NEG studies, is typically chosen on the basis of the 'older' empirical literature on international trade, more specifically on the estimation of the so-called gravity equation of which (9) is an example (see Anderson and van Wincoop (2004) for an extensive discussion of the gravity equation). Usually, and probably mostly for ease 
of estimation (see Hummels, 2001), the trade cost function takes the following (multiplicative) form,

$$
T_{i j}=\prod_{m=1}^{M} X_{i j}^{\gamma_{m}} \prod_{k=1}^{K}\left(X_{i}^{\gamma_{1 k}} X_{j}^{\gamma_{2 k}}\right) v_{i j}
$$

where the unobservable part, $v_{i j}$, of the trade cost function is modelled by a

disturbance term (that is usually assumed to be i.i.d.). To give an idea about the type of trade cost function used in the NEG wage equation studies, Table 1 below shows the trade cost function used in several NEG papers including Hanson (2005) and Redding and Venables (2004).

Table 1 Trade cost functions used in the empirical literature

\begin{tabular}{|c|c|c|}
\hline paper & sample & trade cost function \\
\hline \multicolumn{3}{|r|}{ Direct estimation } \\
\hline $\begin{array}{l}\text { Hanson } \\
(2005)\end{array}$ & $\begin{array}{l}\text { US } \\
\text { counties }\end{array}$ & $T_{i j}=\exp \left(\tau D_{i j}\right)$ \\
\hline $\begin{array}{l}\text { Brakman et al. } \\
(2004)\end{array}$ & $\begin{array}{l}\text { German } \\
\text { regions }\end{array}$ & $T_{i j}=\tau^{D_{i j}}$ \\
\hline $\begin{array}{l}\text { Brakman et al. } \\
\text { (2006) }\end{array}$ & $\begin{array}{l}\text { European } \\
\text { regions }\end{array}$ & $T_{i j}=\tau D_{i j}^{\delta}$ \\
\hline $\begin{array}{l}\text { Mion } \\
(2004)\end{array}$ & $\begin{array}{l}\text { Italian } \\
\text { regions }\end{array}$ & $T_{i j}=\exp \left(\tau D_{i j}\right)$ \\
\hline \multicolumn{3}{|c|}{ Two-step estimation } \\
\hline $\begin{array}{l}\text { Redding and Venables } \\
\text { (2004) }\end{array}$ & $\begin{array}{l}\text { World } \\
\text { countries }\end{array}$ & $\begin{aligned} T_{i j}=D_{i j}^{\delta} \exp \left(\alpha B_{i j}\right) \exp \left(\beta_{1} i s l_{i}+\beta_{2} i s l_{j}+\right. \\
\left.\quad \beta_{3} \text { llock }_{i}+\beta_{4} \text { llock }_{j}+\beta_{5} \text { open }_{i}+\beta_{6} \text { open }_{j}\right)\end{aligned}$ \\
\hline $\begin{array}{l}\text { Knaap } \\
(2006)\end{array}$ & $\begin{array}{l}\text { US } \\
\text { states }\end{array}$ & $T_{i j}=D_{i j}^{\delta} \exp \left(\alpha B_{i j}\right)$ \\
\hline $\begin{array}{l}\text { Breinlich } \\
(2006)\end{array}$ & $\begin{array}{l}\text { European } \\
\text { regions }\end{array}$ & $T_{i j}=D_{i j}^{\delta} \exp \left(\alpha_{1} L_{i j}+\sum_{i} \alpha_{2 i} B_{i j}^{i}\right)$ \\
\hline $\begin{array}{l}\text { Hering and Poncet } \\
(2006)\end{array}$ & $\begin{array}{l}\text { Chinese } \\
\text { cities }\end{array}$ & $T_{i j}=D_{i j}^{\delta} \exp \left(\alpha_{1} B_{i j}^{f}+\alpha_{2} B_{i j}^{C}+\alpha_{3} B_{i j}^{f C}\right)$ \\
\hline
\end{tabular}

Notes: $D_{i j}$ denotes a measure of distance, usually great-circle distance, but sometimes also other measures such as travel times (e.g. Brakman et al., 2004) or population weighted great-circle distance (e.g. Breinlich, 2006) have been used. $B_{i j}$ denotes a border dummy, either capturing the (alleged positive) effect of two countries/regions being adjacent (e.g. Redding and Venables, 2004; Knaap, 2006) or the (possibly country-specific) effect of crossing a national border (e.g. Breinlich, 2006; Hering and Poncet, 2006).

As can be seen from Table 1, the trade cost function imposed differs quite a bit between these papers and between the 2 estimation strategies. Or, to quote Anderson 
and van Wincoop (2004): “A variety of ad hoc trade cost functions have been used to relate the unobservable cost to observable variables (p.706)” and “Gravity theory (read: new economic geography theory) has used arbitrary assumptions regarding functional form of the trade cost function, the list of variables, and regularity conditions (p.710, phrase in italics added)”. To a large extent based on Anderson and van Wincoop (2004), our discussion of the (implicit) assumptions underlying the use of a trade cost function concerns six issues: i) functional form, ii) variables included, iii) regularity conditions, iv) modelling costs involved with internal-trade, v) the unobservable component of trade costs, vi) estimating the trade cost function's parameters.

i) functional form. All papers in Table 1 have to assume a specific functional form for the trade cost function. As can be seen from Table 1, empirical papers in NEG opt for a functional form as shown in (13); all cost factors enter multiplicatively. As in the international trade literature (see Hummels, 2001), the main reason for doing so is probably ease of estimation. Although being by far the most common functional form used in the empirical NEG and the international trade literature, its implications are usually not given much attention. As pointed out by Hummels (2001), the multiplicative form implies that the marginal effect of a change in one of the trade cost components depends on the magnitude of all the other cost factors included in the trade cost function. As this may not be that realistic he argues that a more sensible trade cost function combines the different cost factors additively, i.e.

$$
T_{i j}=\sum_{m}^{M} \gamma_{m} X_{i j}+\sum_{k}^{K}\left(\gamma_{1 k} X_{i}+\gamma_{2 k} X_{j}\right)+v_{i j}
$$

where $X_{i j}, X_{i}, X_{j}$ and $v_{i j}$ are defined as in (12). Using this specification avoids the above-mentioned problem, as each cost factor's marginal effect does no longer depend on the magnitude of the other cost factors. In estimating the wage equation in section 6, we will therefore use both a multiplicative and additive trade cost function and check whether this makes a real difference or not.

Also the specific distance funtion chosen is of concern. Some papers take an exponential distance function (Hanson, 2005; Brakman et al., 2004 and Mion, 2004), hereby following the theoretical NEG literature (e.g. Fujita et al., 1999 and Krugman, 1995). The other papers shown in Table 1 opt for the power function instead, which is also the standard choice in the empirical trade literature. As argued by Fingleton and McCann (2007) the latter function has the virtue of allowing for economies of 
distances ${ }^{9}$, so that transport costs are concave in distance (standard in the transportation and logistics literature, see e.g. McCann, 2001), whereas the exponential distance function implies that transport costs are convex in distance. It also implicitly imposes a very strong distance decay, which may not be wanted (see Head and Mayer, 2004).

ii) variables included. The number and composition of variables included in the trade cost function differs quite substantially across the papers in Table 1 . The papers employing the direct estimation strategy only include distance in the trade cost function. The impact of assuming a more elaborate trade cost function when applying the direct estimation strategy is shown in section 6. Studies employing the two-step estimation strategy usually also take other bilateral trade cost proxies into account besides distance, see the variables $L_{i j}$ and $B_{i j}$ in Table 1, capturing the effect of language similarity and the border effect respectively. ${ }^{10}$

When it comes to the inclusion of potentially relevant variables capturing country-specific trade costs, a drawback of the second estimation strategy as outlined in section 2 is that the inclusion of the importer and exporter dummies (recall equations (9) and (10)) wipes out all importer specific and exporter specific variation so that the effect of country-specific trade cost proxies cannot be estimated. As a result, the constructed market (supplier) access term (10) includes only the exporter (importer) specific trade costs and misses those trade costs specific to the importer (exporter) $^{11}$. Implicitly all the papers using the two-step estimation strategy cum dummies approach mentioned in Table 1 assume that country-specific trade costs are zero. Redding and Venables (2004, pp.76-77) take note of this by also estimating the trade equation (9) without capturing the market and supplier capacity terms by importer and exporter dummies but by using importer and exporter GDP instead,

\footnotetext{
${ }^{9}$ When the estimated distance parameter has to be between zero and minus one.

${ }^{10}$ Even though these papers include some more variables in the trade cost function, many additional variables have been shown to be of importance in the empirical trade literature. Examples are tariffs, colonial ties, quality of infrastructure, degree of openness, being member of a common currency union, the World Trade Organization or some preferential trade agreement (NAFTA, EU, Mercosur) and many more (see Anderson and van Wincoop, 2004).

${ }^{11}$ The estimated exporter/importer dummy would in this case also pick up the exporter/importer specific trade costs so that market and supplier access would implicitly look like (in case of a multiplicative trade cost function:

$$
M \hat{A}_{i}=\sum_{j}^{r}\left[\hat{m}_{j} \prod_{k=1}^{K}\left(X_{j}^{\hat{\gamma}_{2 k}}\right) \prod_{m=1}^{M} X_{i j}^{\hat{\gamma}_{m}}\right] \text { and } S \hat{A}_{j}=\sum_{i}^{r}\left[\hat{s}_{i} \prod_{k=1}^{K}\left(X_{i}^{\hat{\gamma}_{1 k}}\right) \prod_{m=1}^{M} X_{i j}^{\hat{\gamma}_{m}}\right]
$$
}

Note that $M A_{i}$ and $S A_{j}$ fails to capture the trade costs specific to country $j$ and country $i$ respectively. 
hereby allowing for a more elaborate trade cost function. We will do the same in our estimations.

Besides the above discussion on which variables to include, also the way to measure a certain included variable differs between papers. The best example is the distance variable that shows up in all the assumed trade cost functions. Usually this is measured as great-circle distance between capital cities (e.g. Redding and Venables, 2004), but others have used great-circle distance between countries'/regions' largest commercial centres or counties'/regions' centroids, population weighted distances (e.g. Breinlich, 2006) or travel times (e.g. Brakman et al., 2004). It is difficult to give a definitive answer to what measure of distance to include and the same applies for other variables (e.g. the border dummy, proxies of infrastructure quality). However, we think two recommendations can be made.

Regarding the general question which variables to include; the appropriateness of the inclusion of a certain variable can (and should) always be tested by assessing its significance. Second, one should be careful with the inclusion of variables that are very likely endogenous. Examples are travel times, population weighted distance measures, quality of infrastructure, institutional setup or even being member of a free trade union. Especially when estimating the parameters of the NEG wage equation, that is itself already (by construction) plagued by endogeneity issues, adding more endogeneity through the trade cost function should in our view be avoided (or properly addressed but this is usually not so easy). The use of proxy variables such as great-circle distance, border and language variables and countries' geographical features such as having direct access to the sea, that can more confidently be considered to be exogenous, should be preferred.

iii) regularity conditions. All papers in Table 1, implicitly or explicitly, make assumptions about the extent to which the impact of each variable included in the trade cost function is allowed to be different for different (pairs of) countries. Most papers assume that the effect of distance, sharing a common border or trading internationally on trade costs is the same for all countries or regions included in the sample. It is however likely that there exists some heterogeneity in the effect of different cost factors (see e.g. Limao and Venables, 2001). Some authors do allow these effects to differ between countries or regions (e.g. Breinlich, 2006 and Hering and Poncet, 2006) but usually do so by imposing ad hoc assumptions regarding the 
way they are allowed to differ ${ }^{12}$. An advantage of the assumption(s) made about the regularity conditions (compared to e.g. assumptions about functional form) is that they can be tested. This has so far not been done, we argue that this should receive some more attention.

iv) internal trade costs. The modeling of the costs associated with withincountry trade is another "problematic" feature in the empirical NEG papers ${ }^{13}$. The need to incorporate some measure of internal trade costs follows directly from the functional form of the wage equation (5). There it is the sum of trade cost weighted market capacities (real market access) that consists of on the one hand foreign real market access, $\sum_{j \neq i}^{R} E_{j} G_{j}^{(\sigma-1)} T_{i j}^{(1-\sigma)}$ but also of domestic real market access, $E_{i} G_{i}^{(\sigma-1)} T_{i i}^{(1-\sigma)}$, which is a measure of own market capacity weighted by internal trade cost. Theoretically these internal trade costs are usually set to zero $\left(T_{i i},=1\right)$. In contrast, all empirical NEG papers proxy the internal trade cost by using an internal trade cost function that solely depends on so-called internal distance, $D_{i i}$, excluding other country specific factors that could influence internal trade costs (see Redding and Venables, 2004, p. 62). More formally:

$$
T_{i i}=f\left(D_{i i}\right) \text {, where almost exclusively } D_{i i}=2 / 3\left(\text { area }_{i} / \pi\right)^{1 / 2}
$$

This often-used specification of $D_{i i}$ reflects the average distance from the center of a circular disk with area $_{i}$ to any point on the disk (assuming these points are uniformly distributed on the disk). Basically own trade costs are simply a function of a country's or region's area, the larger the country or region, the higher the internal trade costs. Also most papers, regardless of estimation strategy, do not allow internal distance to have a different effect than bilateral distance (an exception are Redding and Venables (2004), who make the ad hoc assumption that the internal distance parameter is half that of the bilateral distance parameter). In section 6 we explicitly estimate a different parameter on internal and bilateral trade and allow own trade costs to depend on other factors that simply internal distance. This and the use of own trade data gives us some indication into the (un)importance of explicitly modelling internal trade costs.

\footnotetext{
${ }^{12}$ Note that assuming the effect to be the same for all countries/regions is also an ad hoc assumption.

${ }^{13}$ Some empirical papers in the international trade literature also deal with this issue (e.g. Helliwell and Verdier, 2001) focussing largely on how to measure interal distances, but in general internal trade costs are not dealt with in this literature due to the fact that internal-trade statistics are hard to obtain.
} 
v) the unobservable component of trade costs. In the direct estimation strategy this component is ignored, thereby implicitly positing that the assumed trade cost function is the actual trade cost function (Breinlich, 2006, also notes this). Taking account of the unobserved component using this strategy is not straightforward. Even if the unobservable component is assumed to be of the simplest kind, i.e. distributed i.i.d. and uncorrelated with any other compenent of either the trade cost function or the wage equation, the non-linear fashion in which it enters the wage equation makes it difficult to determine the appropriateness of the inference on the structural parameters when simply assuming it away (or equivalently assuming it is nicely incorporated into the error component of the wage equation itself). Simulation based inference methods could (and maybe should) be a way to shed more light on this issue.

When using the two-step estimation strategy the unobserved trade cost component(s) is (are) more explicitly taken into account. They are usually assumed to be uncorrelated with the other (observable) trade cost components and to be independent draws from a lognormal distribution, so that they can be incorporated as a (possibly heteroscedastic) normal error term in the first step estimation of the gravity equation (9). Next the use of bootstrapped standard errors in the $2^{\text {nd }}$ step estimation aims to take account of the fact that the market and supplier access terms (constructed on the basis of the estimated parameters of the first step) implicitly contain the unobservable trade cost component as well, i.e. they are both generated regressors.

vi) estimating the trade cost function's parameters and dealing with zero trade flows. This is only an issue when using the two-step estimation strategy, where, as explained in section 2, the parameters of the trade cost function are estimated in the first step by making use of a gravity-type equation. A well-known problem with the estimation of gravity equations is the presence of a substantial number of bilateral trade flows that are zero (i.e. countries not trading bilaterally at all). To deal with this different estimation strategies have been put forward. These can be grouped into two categories, i.e those estimating the loglinearized trade equation (9) and those estimating the non-linear trade equation (8). Because taking logs of the zero trade flows is problematic, the loglinearized version of the trade equation (9) is usually estimated using OLS and the non-zero trade flows only, or, by first adding 1 (or e.g. the smallest non-zero trade flow) to all or only the zero trade flows, and subsequently 
estimating the trade cost function's parameters by OLS or Tobit. When estimating the non-linear trade equation (8) instead, either NLS (Coe et al., 2002) or the recently proposed Poison pseudo maximum likelihood (PPML) estimator (Santos Silva and Tenreyro, 2006) can be used, in this case all trade flows can be used (the zero trade flows can now also be used as there is no need to take logs).

Arbitrarily adding 1 (or some other positive number) to trade flows in order to be able to take logs of all (also the zero) trade flows is in our view highly unsatisfactory. The subsequent results obtained depend quite strongly on the actual amount that is added to the zero trade flows. Using the non-linear techniques solves this issue and can therefore be considered as a preferred way to estimate the trade function's parameters. This is why we opt for the estimation of the non-linear trade equation (8) using the PPML estimator.

To summarize, Table 2 lists the issues that one has to face when approximating trade costs by a trade cost function, while also providing possible ways to deal with these issues.

Table 2 Trade cost functions and the two estimation strategies

\begin{tabular}{|c|c|c|c|}
\hline \multirow[b]{2}{*}{ issue } & \multirow[b]{2}{*}{ (possible) solution } & \multicolumn{2}{|c|}{ Ability do deal with issue raised } \\
\hline & & Two-step & Direct \\
\hline functional form & $\begin{array}{l}\text { experiment with } \\
\text { different functional } \\
\text { forms }\end{array}$ & + & $\begin{array}{c}- \\
\text { (non-linearity) }\end{array}$ \\
\hline $\begin{array}{l}\text { regularity } \\
\text { conditions }\end{array}$ & test the assumptions & + & + \\
\hline $\begin{array}{l}\text { variable } \\
\text { inclusion }\end{array}$ & $\begin{array}{l}\text { significance of } \\
\text { inclusion can be tested }\end{array}$ & $\begin{array}{c}+- \\
\text { (difficulty with exporter } \\
\text { /importer specific trade } \\
\text { costs when using } \\
\text { dummies) }\end{array}$ & + \\
\hline $\begin{array}{l}\text { variable } \\
\text { measurement }\end{array}$ & $\begin{array}{l}\text { include exogenous } \\
\text { variables }\end{array}$ & + & + \\
\hline $\begin{array}{l}\text { internal trade } \\
\text { cost }\end{array}$ & $\begin{array}{l}\text { include more than } \\
\text { simply area }\end{array}$ & $\begin{array}{c}+- \\
\text { (unavailability of internal } \\
\text { trade data) }\end{array}$ & + \\
\hline $\begin{array}{l}\text { unobservable } \\
\text { component }\end{array}$ & $\begin{array}{l}\text { most hidden issue, } \\
\text { deserves more explicit } \\
\text { care }\end{array}$ & + & $\begin{array}{c}- \\
\text { (implicitly assumed away) }\end{array}$ \\
\hline $\begin{array}{l}\text { estimating the } \\
\text { parameters }\end{array}$ & $\begin{array}{l}\text { non-linear estimation } \\
\text { techniques (PPML) }\end{array}$ & (non-zero trade flows) & $\begin{array}{l}+ \\
\text { (NLS should do the job, } \\
\text { given the other } \\
\text { assumptions) }\end{array}$ \\
\hline
\end{tabular}

Notes : + and - indicates the abilitity of the corresponding estimation strategy to deal with the issue raised w.r.t. to the choice of trade cost function that is used (compared to the other strategy). 


\section{A THIRD ESTIMATION STRATEGY: IMPLIED TRADE COSTS}

Now that we have, at some length, discussed the (implicit) choices one has to make when using a trade cost function to approximate trade costs, $T_{i j}$, in this section we introduce a third option where the need to specify a trade cost function does not arise. This is based on Head and Ries (2001) who provide a clever way to infer trade costs. Using the trade equation (8) and making two important assumptions (see below), they show that trade costs can be inferred from trade data in the following way:

$$
T_{i j}^{1-\sigma} \equiv \varphi_{i j}=\sqrt{\frac{E X_{i j} E X_{j i}}{E X_{i i} E X_{j j}}}
$$

where $E X_{i j}$ denotes imports of country $j$ from country $i$ and $E X_{i i}$ denotes the total amount of goods consumed in country $i$ that is also produced in country $i$. Moreover $\varphi_{i j}$ is introduced for notational convenience as a measure of the so-called 'free-ness' of trade (see Baldwin et al., 2003). It ranges from 0 to 1, with 0 meaning prohibitive and 1 meaning completely free trade. Head and Ries (2001) use this method to construct implied trade costs for bilateral trade (disaggregated at the industry level) between the US and Canada. They show the gradual decline in trade costs over time and use regression methods to decompose it into a tariff and a non-tariff barrier component. Other papers that have also used (16) to construct implied trade costs are Head and Mayer (2004) and Brakman et al. (2006), they subsequently use them as a comparison to the theoretical breakpoints following from NEG models or, as Head and Ries (2001) do, to follow their evolution over time.

We argue that (16) can also be used in the estimation of the wage equation. Instead of proxying trade costs by making use of a trade cost function, resulting in the (implicit) assumptions summarized by Table 2, implied trade costs provide an alternative estimation strategy. But the use of implied trade costs (unfortunately) also has its problems. First, there is the additional data requirement. As can be readily seen from (16) the construction of implied trade costs requires the availability of trade with oneself, $E X_{i i}$, for all countries in the data set. Own-trade data are usually not readily available, but when both total export and production data are available they can be constructed as total a country's or region's own production minus exports (see e.g. Head and Mayer, 2004; Head and Ries, 2001; Hering and Poncet, 2006). It is only in the complete absence of bilateral trade data, as is typically the case when working 
with data at the regional level (e.g. in the case of Europe, see Breinlich, 2006) that implied trade costs can not be used at all.

Secondly, and turning to the implicit assumptions made when constructing implied trade costs using (16), two assumptions are needed in order for the implied trade cost approach to work. They follow directly from the way these implied trade costs are calculated. Substituting (8) for both bilateral and internal trade, we arrive at (16) in the following way:

$$
\sqrt{\frac{E X_{i j} E X_{j i}}{E X_{i i} E X_{j j}}}=\sqrt{\frac{T_{i j}^{1-\sigma} T_{j i}^{1-\sigma}}{T_{i i}^{1-\sigma} T_{j j}^{1-\sigma}}} \underset{\text { (assumption } A)}{=} \sqrt{T_{i j}^{1-\sigma} T_{j i}^{1-\sigma}} \underset{\text { (assumption } B)}{=} T_{i j}^{1-\sigma}=\varphi_{i j}
$$

Where the following two assumptions are made:

$$
\begin{array}{lll}
\text { (A) } & T_{i i}=1 & \forall i \\
\text { (B) } & T_{i j}=T_{j i} & \forall i, j
\end{array}
$$

That is to say, $(A)$ internal trade costs are negligible and $(B)$ trade costs involved when shipping from country $i$ to country $j$ are the same as shipping from country $j$ to country $i$. Whether these assumptions are valid is an empirical matter to which we return in section 6 when discussing our estimation results. How do these two assumptions relate to the assumptions made when a trade cost function is used instead? Table 3 shows this on the basis of the six issues that were already discussed

\begin{tabular}{|c|c|c|}
\hline issue & Trade cost function & Implied trade costs \\
\hline functional form & assumed & not an issue \\
\hline regularity conditions & $\begin{array}{l}\text { ad hoc assumptions } \\
\text { are (implicitly) made }\end{array}$ & $\begin{array}{l}\text { symmetry of bilateral trade } \\
\text { costs }\end{array}$ \\
\hline $\begin{array}{l}\text { variable } \\
\text { inclusion }\end{array}$ & $\begin{array}{l}\text { many candidates, } \\
\text { which ones to include? }\end{array}$ & not an issue \\
\hline $\begin{array}{l}\text { variable } \\
\text { measurement }\end{array}$ & $\begin{array}{l}\text { no consensus, } \\
\text { choices need to be made }\end{array}$ & not an issue \\
\hline internal trade cost & $\begin{array}{l}\text { assumed to depend on internal } \\
\text { distance }\end{array}$ & assumed to be negligible \\
\hline $\begin{array}{l}\text { unobservable } \\
\text { component }\end{array}$ & $\begin{array}{l}\text { needs explicit care } \\
\text { (additional assumptions) }\end{array}$ & implicitly taken into account \\
\hline $\begin{array}{l}\text { estimating the } \\
\text { parameters }\end{array}$ & $\begin{array}{l}\text { choice of estimation method } \\
\text { not always straightforward }\end{array}$ & not necessary \\
\hline
\end{tabular}
in section 2, with assumptions (A) and (B) in bold in Table 3.

Table 3 Trade cost function vs. implied trade costs

The potential advantage of using implied trade costs clearly comes to the fore. But this verdict, of course, depends on the alleged innocence of assumptions (A) and (B). 
As to the assumption of symmetric bilateral trade costs, this assumption is also quite common in the empirical NEG studies that use a trade cost function. All the papers mentioned in Table 1 use a trade cost function that (implicitly) assumes symmetric bilateral trade costs (the only exception being the second trade cost specification from Redding and Venables, 2004 in Table 1). Arguably the most problematic assumption when using implied trade costs is the assumption of negligible internal trade costs. Although virtually all theoretical results in NEG are established while using this assumption, many authors (Anderson and van Wincoop, 2005; Head and Mayer, 2004) have stressed the importance of dropping this assumption when doing empirical work. But given the other above-mentioned virtues of using implied trade costs, combined with the fact that theoretically these internal trade costs are also usually absent, we argue that they should be considered as a "third way" to deal with trade costs in empirical NEG studies.

The remainder of our paper deals with the impact of using different ways to proxy trade costs when estimating the NEG wage equation using either the direct or two-step estimation strategy. Hereby we focus in particular on the way conclusions about real market access, a key NEG variable, may differ when using different methods to proxy trade costs.

\section{DATA}

Our empirical results are based on a sample of 97 countries (see Appendix A for a complete list of these countries) for the year 1996. In order to be able to estimate the wage equation, we have collected data on gdp, gdp per capita (as wage data is not available for all countries in our sample, we follow Redding and Venables (2004) and use gdp per capita as a proxy) and the price index of gdp (as a proxy for $G_{i}$ in $(7)^{14}$ ) from the Penn World Tables. We also need data to calculate the various trade cost proxies. To this end, we have collected data on bilateral distances, contiguity, common language, and indicators of a country being landlocked, an island nation, or a Sub-Saharan African country. All these variables are chosen because of their exogeneity (at least in terms of reverse causality). Complementing these data, we also need trade data to be able to calculate implied trade costs and to be able to infer the trade cost function's parameter(s) when using the two-step estimation strategy. These

\footnotetext{
${ }^{14}$ Note that theoretically the price index should only refer to that of tradable goods. Using the overall price index as a proxy does also capture the price of nontradables.
} 
we have collected from the Trade and Production 1976-1999 database provided by the French institute CEPII ${ }^{15}$, which enables the use of both bilateral trade and internal trade data for most of the countries in our sample.

\section{ESTIMATION RESULTS: TRADE COSTS AND MARKET ACCESS}

In line with the discussion so far, we discuss our results in two stages. First, we focus on inferring trade cost proxies from bilateral trade data. We estimate the parameters of the trade cost function and illustrate how the results differ when using different trade cost functions. We also calculate implied trade costs and check how much of these implied trade costs can be explained by a particular trade cost function. In the process we look into some evidence regarding the relevance of the assumptions made when using implied trade costs as a proxy for $T_{i j}$ (recall assumptions $18 \mathrm{~A}$ and $18 \mathrm{~B}$ from section 4). Subsequently, we turn to our main point of interest, i.e. the way in which a particular trade cost approximation affects conclusions about the relevance of real market access in determining gdp per capita. This is done by estimating the wage equation using the different trade cost proxies, and by comparing the size and significance of the parameter on market access $\left(\alpha_{3}\right)$ in equation (11) for each of the trade cost proxies used. Moreover, we look for our main trade costs specifications at the spatial reach of economic shocks to market access by simulating the effects of a $5 \%$ gdp shock in Belgium on gdp per capita in other countries. In this way, we can gauge the importance of varying the trade costs specifications for the relevance of spatial interdependencies, the backbone of the NEG literature.

Besides implied trade costs, we distinguish between 4 different types of trade cost functions, Table 4 shows these four trade cost functions. The first two trade cost functions are chosen as they are the ones used by the two papers that respectively introduced the two-step and direct estimation strategy, Redding and Venables (2004, RV) and Hanson (2005). The multiplicative function is chosen as it allows trade costs to depend not only on bilateral variables but also on importer/exporter specific trade cost factors, more specifically those associated with being landlocked (llock), being an island nation (isl) and being a Sub-Saharan African country (ssa). As mentioned before, such a multiplicative function is quite common in the empirical trade literature (see e.g. Limao and Venables, 2001).

\footnotetext{
${ }^{15} \mathrm{http}: / /$ www.cepii.org/anglaisgraph/bdd/TradeProd.htm
} 
Table 4

Trade cost functions used

\begin{tabular}{lc}
\hline \multicolumn{1}{c}{ Abbreviation } & trade cost function \\
\hline RV & $T_{i j}=D_{i j}^{\delta} \exp \left(\alpha B_{i j}\right)$ \\
& $T_{i j}=\exp \left(\tau D_{i j}\right)$ \\
\hline multiplicative & $T_{i j}=D_{i j}^{\delta} \exp \left(\alpha_{1} B_{i j}+\alpha_{2} L_{i j}\right) \exp \left(\beta_{1} i s l_{i}+\beta_{2} i s l_{j}+\right.$ \\
& $\left.\beta_{3} l l o c k_{i}+\beta_{4} l l o c k_{j}+\beta_{5} s s a_{i}+\beta_{6} s s a_{j}+\beta_{7} s s a_{i j}\right)$ \\
additive & $T_{i j}=D_{i j}^{\delta}+\alpha_{1} B_{i j}+\alpha_{2} L_{i j}+\beta_{1} i s l_{i}+\beta_{2} i s l_{j}+$ \\
& $\beta_{3} l l o c k_{i}+\beta_{4} l l o c k_{j}+\beta_{5} s s a_{i}+\beta_{6} s s a_{j}+\beta_{7} s s a_{i j}$ \\
\hline
\end{tabular}

See also Table 1 for the definition of the variables.

The additive function is picked to address the critique (Hummels, 2001) on the use of a multiplicative trade function. We also allow for the distance parameter to be different for bilateral and internal distance, hereby estimating (instead of imposing) the different impact of distance when considering intra- vs international trade. Estimating instead of assuming the coefficient on internal distance should in our view be preferred compared to making ad hoc assumptions about it.

\subsection{Inferring trade costs from trade flows}

\subsubsection{Inferring the trade cost function's parameters from trade flows}

To infer the trade cost function's parameters from bilateral (and internal) trade flows we estimate equation (8) by using the PPML estimation strategy ${ }^{16}$. This estimation strategy is, see section 3, able to take account of the zero trade flows in a way that (contrary to NLS) also deals with the heteroscedasticity that is inherently present in trade flow data (see Santos Silva and Tenreyro, 2006). Being able to deal with the zero trade flows without having to impose additional (arbitrary) assumptions, gives the PPML method an advantage over the heavily used Tobit and/or OLS methods. Table 5 shows our estimation results.

To allow for the more elaborate multiplicative and additive trade cost functions we (following Redding and Venables, 2004, p. 76, see their equation (22)) substituted the importer and exporter dummies with importer and exporter gdp ${ }^{17}$. In

\footnotetext{
${ }^{16}$ Except for the additive specification, where we, due to the inability of the PPML method to readily perform non-linear poisson regressions, use NLS.

${ }^{17}$ For sake of comparison we have also estimated the trade equation including importer and exporter dummies while using the corresponding RV trade cost function (eq. 16 in their paper). The results
} 
all specifications the distance coefficient is significant: the further apart two countries , the higher trade costs.

Table 5 Trade costs functions and trade flows - PPML estimation

\begin{tabular}{|c|c|c|c|c|}
\hline \multicolumn{5}{|c|}{ Trade flows } \\
\hline Trade cost function: & RV & Hanson & multiplicative & additive \\
\hline distance & -0.721 & -0.0002 & -0.712 & -1.035 \\
\hline \multirow{2}{*}{ internal distance } & $\begin{array}{c}0.000 \\
0.034\end{array}$ & $\begin{array}{c}0.000 \\
-0.001\end{array}$ & $\begin{array}{c}0.000 \\
0.050\end{array}$ & $\begin{array}{c}0.000 \\
-0.047\end{array}$ \\
\hline & 0.745 & 0.000 & 0.650 & 0.676 \\
\hline \multirow{2}{*}{ contiguity } & 0.746 & - & 0.930 & 0.000 \\
\hline & 0.000 & - & 0.000 & 0.424 \\
\hline \multirow[t]{2}{*}{ common language } & - & - & 0.007 & 0.000 \\
\hline & - & - & 0.962 & 0.523 \\
\hline \multirow[t]{2}{*}{ landlocked importer } & - & - & -0.441 & 0.000 \\
\hline & - & - & 0.045 & 0.295 \\
\hline \multirow[t]{2}{*}{ landlocked exporter } & - & - & -0.257 & 0.000 \\
\hline & - & - & 0.003 & 0.513 \\
\hline \multirow[t]{2}{*}{ island importer } & - & - & 0.285 & 0.000 \\
\hline & - & - & 0.000 & 0.284 \\
\hline \multirow[t]{2}{*}{ island exporter } & - & - & 0.526 & 0.000 \\
\hline & - & - & 0.000 & 0.307 \\
\hline \multirow[t]{2}{*}{ ssa importer } & - & - & -0.801 & 0.000 \\
\hline & - & - & 0.000 & 0.281 \\
\hline \multirow[t]{2}{*}{ ssa exporter } & - & - & -1.052 & 0.000 \\
\hline & - & - & 0.000 & 0.635 \\
\hline \multirow[t]{2}{*}{ ssa importer and exporter } & - & - & 0.950 & 0.000 \\
\hline & - & - & 0.004 & 0.692 \\
\hline \multirow[t]{2}{*}{ gdp importer } & 0.751 & 0.743 & 0.733 & 1.070 \\
\hline & 0.000 & 0.000 & 0.000 & 0.000 \\
\hline \multirow[t]{2}{*}{ gdp exporter } & 0.851 & 0.838 & 0.841 & 0.976 \\
\hline & 0.000 & 0.000 & 0.000 & 0.000 \\
\hline exporter dummies & no & no & No & no \\
\hline importer dummies & no & no & No & no \\
\hline \multirow[t]{2}{*}{ own trade dummy } & 1.599 & 3.810 & 2.431 & 7.330 \\
\hline & 0.008 & 0.000 & 0.000 & 0.216 \\
\hline (pseudo) R2 & 0.953 & 0.943 & 0.956 & 0.982 \\
\hline nr. obs. & 8774 & 8774 & 8774 & 8774 \\
\hline \multicolumn{5}{|l|}{ importer = exporter? } \\
\hline - landlocked & - & - & 0.386 & 0.455 \\
\hline - island & - & - & 0.192 & 0.502 \\
\hline - ssa & - & - & 0.275 & 0.343 \\
\hline
\end{tabular}

Notes: p-values underneath the coefficient; importer = exporter? shows the p-value of a test of equality of the importer and exporter variant of a certain country specific variable.

were very similar to the results shown here when including importer and exporter gdp, also in terms of explanatory power $\left(\mathrm{R}^{2}\right)$ and in terms of the implication in the $2^{\text {nd }}$ step estimation on the effect of market access. Results available upon request. For sake of comparison we do show the results when estimating the wage equation using the 1st-step results for the RV trade cost function with trade dummies as an input in section 6.2. 
Also sharing a common border (contiguity) significantly lowers trade costs (except in the additive specification), a finding consistent with earlier studies (e.g. Limao and Venables, 2001 and Redding and Venables, 2004). When estimating the multiplicative specification, the results show the importance of also considering country-specific trade cost proxies. Being landlocked or a Sub-Saharan African country raises trade costs, whereas being an island lowers these costs. These findings are very much in line with the results reported in Limao and Venables (2001) and show that these country-specific trade cost proxies cannot a priori be ignored. Things are rather different when considering the additive trade cost specification: except for distance no other variable is significant. We think that the increased non-linearity of the additive trade cost function is (at least partly) to blame for this. These estimation difficulties for the additive trade cost function are something to take explicit note of (we will return again to this issue when estimating the wage equation), and it limits in our view the usefulness of such a functional form.

Of explicit interest here is the coefficient on internal distance (the coefficient shown reflects the difference of the internal distance coefficient with that of bilateral distance). When using the RV, the multiplicative or the additive specification we find no evidence that internal distance affects trade costs significantly different than bilateral distance does. Only when using the Hanson specification we find that internal distance affects trade costs significantly different from bilateral trade, the estimated coefficient suggests that internal distance increases trade costs to a much larger extent than bilateral distance does, which is contrary to what one would expect.

\subsubsection{Implied trade costs and trade cost functions}

Next we turn to the alternative way to infer trade costs from trade data, namely by calculating implied trade costs as shown by equation (17) in section 4. Doing this for our sample leaves us with no less than 3808 observed bilateral $\varphi_{i j}$ 's. How much of these implied trade costs can be accounted for by the four different trade cost functions used in the previous sub-section? Or, to put it differently, does the use of implied trade costs provide a proxy for trade costs that differs from the proxy obtained using trade cost functions in Table 5? And what about the (ir)relevance of the underlying assumptions when calculating implied trade costs, see (18A,B)? 
To answer the first question we regressed the bilateral $\varphi_{i j}$ 's on each of the four different trade cost functions introduced in the previous section.

Table 6: $\quad$ Trade cost functions and implied trade costs

\begin{tabular}{lcccc}
\hline \multicolumn{5}{c}{ Implied trade costs (phi) } \\
\hline Trade cost function: & $\mathrm{RV}$ & Hanson & multiplicative & additive \\
\hline distance & -0.854 & -0.0002 & -0.850 & -1.352 \\
contiguity & 0.000 & 0.000 & 0.000 & 0.000 \\
& 0.707 & - & 0.8630 & 0.016 \\
common language & 0.139 & - & 0.015 & 0.141 \\
& - & - & -0.226 & 0.001 \\
landlocked & - & - & 0.152 & 0.425 \\
& - & - & -1.376 & -0.030 \\
island & - & - & 0.000 & 0.013 \\
& - & - & 0.289 & 0.003 \\
ssa & - & - & 0.177 & 0.001 \\
& - & - & -1.153 & 0.000 \\
ssa both & - & - & 0.000 & 0.929 \\
& - & - & 0.113 & -0.002 \\
& - & - & 0.767 & 0.307 \\
(pseudo) R2 & 0.113 & 0.058 & 0.145 & 0.221 \\
nr. obs. & 3808 & 3808 & 3808 & 3808 \\
\hline
\end{tabular}

Notes: p-values underneath the coefficient.

Table 6 shows the results that are again obtained using the PPML estimator to take account of the zeros in implied trade costs. Note that because of assumption (18B) we cannot split the country-specific trade cost proxies into an exporter and an importer part, so that each country-specific trade cost proxy enters only once.

As can be readily seen from the (pseudo) $\mathrm{R}^{2}$ for each of the four regressions, the trade cost functions capture at most $22 \%$ of the variation in implied trade costs. In case of the "Hanson" trade cost function this is only 5\%! Apparently, approximating trade costs through implied trade costs differs quite a bit from obtaining these costs by estimating the parameters of an a priori specified distance function. Note also that the inclusion of country-specific trade cost proxies does improve the fit ${ }^{18}$. The flexibility of implied trade costs (recall Table 3) as compared to the use of trade cost functions provides a useful alternative way to proxy trade costs in our view.

This last conclusion depends, however, crucially on the validity of the 2 assumptions underlying the calculation of implied trade costs; see (18A,B). To shed

\footnotetext{
${ }^{18}$ The inclusion of country dummies improves the fit even (results available upon request) further suggests that implied trade costs are capturing (unobserved) country-specific trade cost factors.
} 
some light on the (ir)relevance of assumption (18B) the last three rows of Table 5 are instructive. As we mentioned before, when one believes that only symmetric bilateral trade cost proxies such as distance, contiguity and sharing a common official language matter, assumption (18B) is automatically satisfied. But we have been argueing that also country-specific proxies such as being landlocked are important to take into account. Allowing these proxies to have a different effect when engaging in import or export, as we have for example done in Table 5, implicitly violates (18B). This is so unless one cannot reject that the coefficients on the importer and exporter variant of a variables are the same. The results of performing such tests are shown in the last three rows of Table 5 and they provide an indication that indeed the assumption of symmetry as imposed by (18B) is not violated in case of the country-specific variables that we have included.

The other assumption, no internal trade costs (18A), is probably a more problematic one. It seems likely that there are some trade costs involved with internal trade. The results in Table 5 all suggest that internal distance can serve as a sufficient proxy for own trade costs. Those results should however be taken with some care. The fact that the observations on own trade are heavily outnumbered by the observations on bilateral trade (by almost a factor of 10), could have its effect on the regression outcomes.

\section{Table $7 \quad$ Trade cost functions and internal trade}

\begin{tabular}{lcccc}
\hline \multicolumn{5}{c}{ internal trade } \\
\hline Trade cost function: & $\mathrm{RV}$ & Hanson & multiplicative & additive \\
\hline distance & -0.195 & -0.001 & -0.176 & -0.162 \\
& 0.152 & 0.000 & 0.240 & 0.238 \\
landlocked & - & - & -0.025 & -0.052 \\
& - & - & 0.927 & 0.638 \\
island & - & - & -0.070 & -0.024 \\
& - & - & 0.836 & 0.848 \\
ssa & - & - & -0.256 & -0.107 \\
& - & - & 0.350 & 0.413 \\
gdp importer & 1.404 & 1.434 & 1.382 & 1.370 \\
& 0.000 & 0.000 & 0.000 & 0.000 \\
& & & & \\
\hline (pseudo) R2 & 0.879 & 0.886 & 0.880 & 0.874 \\
nr. obs. & 93 & 93 & 93 & 93 \\
\hline
\end{tabular}

Notes: p-values underneath the coefficient. 
To check for this, we estimated each of the trade equations using only the data on internal trade. The results are shown in Table 7 above.

Except in case of the Hanson distance function, none of the included trade cost proxies is found to be significant in explaining the variation in internal trade. In case of the country-specific variables this may not be that surprising (why should it matter for a country's internal trade costs whether or not it is an island or landlocked?). What is most striking is that also internal distance, the widely used proxy for internal trade costs, mostly turns out to be insignificant (again except in the Hanson specification) ${ }^{19}$. The results shown in Table 7 can, of course, not be taken as conclusive evidence that internal trade costs are indeed negligible and that assumption (18A) can therefore be taken for granted. They do, however, serve as an indication that the way internal trade costs are proxied when specifying them within the trade cost function approach, is also far from straightforward. Proxying internal trade costs by a clever transformation of a region's or a country's area, as is done by virtually all empirical NEG papers, may be just as harmful as assuming them away.

\subsection{Varying trade costs and the impact on market access}

We are now finally in a position to turn to our main point of interest, the way in which the various trade cost approximations may affect conclusions as to the relevance of real market access in determining gdp per capita levels in our sample. To this end, we estimate wage equation (7) using both the direct and the 2-step estimation strategies introduced in section 2, i.e. to refresh our memory:

$$
\ln w_{i}=\alpha_{1}+\alpha_{2} \ln G_{i}+\alpha_{3} \ln \left(\sum_{j}^{R} E_{j} G_{j}^{(\sigma-1)} T_{i j}^{(1-\sigma)}\right)+\eta_{i}
$$

We focus on the size and significance of the parameter on market access $\left(\alpha_{3}\right)$ when using the different trade cost proxies (this section) as well as when looking at the spatial reach of economic shocks (next section). For the direct estimation strategy as developed by Hanson (2005), we use NLS to estimate the parameters whereby we proxy $G_{i}$ by a country's price index and $E_{i}$ by a country's gdp level. When using the 2-step estimation method as developed by Redding and Venables (2004), we construct

\footnotetext{
${ }^{19}$ Considering that internal distance is merely capturing the area or the size of a country, this may indeed not be so surprising after all. Why should a larger country always face higher internal trade or transport costs (compare transportation within the USA against that of transportation within Sierra Leone)?
} 
market access as specified in (10) on the basis of the results shown in Table 5 and estimate (7) by simple OLS, again proxying $G_{i}$ by a country’s price index. We could have instead used more sophisticated GMM or 2SLS techniques that have been used in the empirical NEG literature and/or have proxied $G_{i}$ by for example a constructed measure of supplier access. But we decided to use OLS and a simple proxy of $G_{i}$, to be able to focus entirely on the effect of the trade cost proxy used on the estimated effect of market access. The use of more sophisticated ways of estimating (7') would make it far more difficult to ascribe different outcomes to the differences in the way trade costs are proxied. For the same reasons, we also assume that the technological differences between countries as measured by, $\eta_{i}$, can be adequately captured by a simple i.i.d. error term that is uncorrelated with the other regressors instead of also adding additional variables.

The results of the various estimations are shown in Table 8a. Each column gives first the estimation strategy used (2-step or direct) and below the trade cost approximation that was used, so $R V$-dum refers for instance to the Redding and Venables trade cost function with im- and exporter dummies and $R V$ to the trade cost function (see Table 5) where gdp is used instead of the trade dummies. Similary, 2step/Hanson (column III in Table 8a) indicates a 2-step estimation of (7') with the Hanson trade cost function.

Tabel 8a. market access and gdp per capita

\begin{tabular}{lcccccccccc}
\hline $\begin{array}{l}\text { Strategy: } \\
\text { Trade } \\
\text { costs: }\end{array}$ & 2-step & RV dum & $\begin{array}{c}\text { 2-step } \\
\text { RV }\end{array}$ & $\begin{array}{c}\text { 2-step } \\
\text { Hanson }\end{array}$ & $\begin{array}{c}\text { 2-step } \\
\text { multiplicative }\end{array}$ & $\begin{array}{c}\text { 2-step } \\
\text { additive }\end{array}$ & $\begin{array}{c}\text { direct } \\
\text { implied }\end{array}$ & $\begin{array}{c}\text { direct } \\
\text { RV }\end{array}$ & $\begin{array}{c}\text { direct } \\
\text { Hanson }\end{array}$ & $\begin{array}{c}\text { direct } \\
\text { multiplicative }\end{array}$ \\
& 0.509 & 0.634 & 0.303 & 0.642 & 0.512 & 0.231 & 0.262 & 0.236 & 0.248 \\
$\alpha_{3}$ & 0.002 & 0.003 & 0.047 & 0.000 & 0.001 & 2.996 & 3.047 & 2.463 & 4.286 \\
& 0.891 & 0.969 & 1.114 & 0.804 & 0.896 & 0.825 & 0.879 & 1.090 & 0.942 \\
& 0.000 & 0.000 & 0.000 & 0.000 & 0.000 & 3.851 & 3.113 & 7.358 & 4.255 \\
R2 & 0.648 & 0.644 & 0.586 & 0.731 & 0.679 & 0.627 & 0.706 & 0.654 & 0.736 \\
nr obs & 80 & 80 & 80 & 80 & 80 & 80 & 80 & 80 & 80 \\
\hline
\end{tabular}

Notes: p-values underneath the coefficient in case of 2-step estimation. T-statistics underneath the coefficient in case of direct estimation.

The first thing to note is that market access is always significant ${ }^{20}$. But the size of the coefficient differs quite a bit across the trade cost proxies and the estimation strategies! The impact of a $1 \%$ increase in a region's market potential on gdp per

\footnotetext{
${ }^{20}$ Notwithstanding differences in the exact specifications used our estimation results for market access in Tables $8 \mathrm{a}$ and $8 \mathrm{~b}$ are at least for the RV case (columns 1 and 2) similar to those in Redding and Venables (2004), see for instance their Table 3.
} 
capita ranges from a minimum of $0.23 \%$ when using implied trade costs to $0.64 \%$ when using the multiplicative trade cost function. When comparing results for each estimation strategy separately, the differences are smaller but still the impact of a $1 \%$ change in market access ranges from $0.23 \%$ to $0.26 \%$ (0.30\% to $0.64 \%)$ when using the direct (2-step) estimation strategy ${ }^{21}$. Table $8 b$ shows additional evidence on the impact of the type of trade cost proxy used. Here we abstracted from the thorny issue of internal trade costs and estimated the effect of only foreign market access (FMA), that is MA excluding a region's own internal distance weighted gdp, on a region's gdp per capita level. Hereby focussing more specifically on the way spatial interdepencies between countries matter for an individual country’s prosperity.

Tabel 8b. foreign market access and gdp per capita

\begin{tabular}{|c|c|c|c|c|c|c|c|c|c|}
\hline $\begin{array}{l}\text { Strategy: } \\
\text { Trade } \\
\text { costs: }\end{array}$ & $\begin{array}{c}\text { 2-step } \\
\text { RV dum }\end{array}$ & $\begin{array}{c}\text { 2-step } \\
\text { RV }\end{array}$ & $\begin{array}{c}\text { 2-step } \\
\text { Hanson }\end{array}$ & $\begin{array}{c}\text { 2-step } \\
\text { multiplicative }\end{array}$ & $\begin{array}{c}\text { 2-step } \\
\text { additive }\end{array}$ & $\begin{array}{l}\text { direct } \\
\text { implied }\end{array}$ & $\begin{array}{c}\text { direct } \\
\text { RV }\end{array}$ & $\begin{array}{c}\text { direct } \\
\text { Hanson }\end{array}$ & $\begin{array}{c}\text { direct } \\
\text { multiplicative }\end{array}$ \\
\hline \multirow[t]{2}{*}{ FMA } & 0.494 & 0.425 & 0.232 & 0.669 & 0.528 & 0.328 & 0.098 & 0.102 & 0.153 \\
\hline & 0.022 & 0.031 & 0.132 & 0.001 & 0.014 & 3.126 & 1.503 & 1.279 & 1.806 \\
\hline \multirow[t]{2}{*}{$a_{2}$} & 1.117 & 1.142 & 1.203 & 0.958 & 1.078 & 0.839 & 1.092 & 1.120 & 1.042 \\
\hline & 0.000 & 0.000 & 0.000 & 0.000 & 0.000 & 4.547 & 8.150 & 7.829 & 7.563 \\
\hline $\mathrm{R} 2$ & 0.601 & 0.592 & 0.571 & 0.708 & 0.633 & 0.672 & 0.628 & 0.607 & 0.645 \\
\hline nr obs & 80 & 80 & 80 & 80 & 80 & 80 & 80 & 80 & 80 \\
\hline
\end{tabular}

Notes: p-values underneath the coefficient in case of 2-step estimation. T-statistics underneath the coefficient in case of direct estimation.

As can be clearly seen from Table 8b the estimated impact of foreign market access differs much more than market access itself, a 1\% increase in foreign market access raises gdp per capita from a mere $0.01 \%$ to $0.67 \%$ depending on the trade cost proxy used. This clearly indicates that the choice of trade costs specification makes quite a difference. Its impact is even estimated to be insignificant at the $5 \%$ level in 4 out of 8 cases. The latter is especially the case for the direct estimation strategy when estimating the trade cost parameters jointly with the NEG parameters (columns 7-9) ${ }^{22}$.

On the basis of these estimation results we conclude that both the size and significance of (foreign) market access does depend on the type of trade cost

\footnotetext{
${ }^{21}$ Note that the difference in size could also be due to the different ways in which market access is constructed. The thought experiment in the next section, which more explicitly describes the spatial reach of an income shock, implicitly shows, by calculating the marginal effects, that this is probably not the case.

${ }^{22}$ As mentioned already in the previous section, this probably is to a large extent due to the non-linear estimation process. The use of more elaborate trade cost functions makes it even 'more non-linear' increasing the difficulties with pinpointing the parameters.
} 
approximation used. This is not the only way to illustrate why the empirical specification matters for NEG empirics. As trade costs are key to the strength of spatial interdependencies, the spatial or geographical reach of income shocks can potentially be very different when comparing different trade costs specifications.

\subsection{Trade costs and the spatial reach of an income shock in Belgium}

To address this issue we conduct the following thought experiment. Suppose that Belgium, a country in the heart of Europe, experiences a positive 5\% gdp shock, to what extent will this shock, given our estimation results in Table 8, spill over to the other countries in our sample through the market access variable? The $5 \%$ increase in gdp increases the demand for goods from potentially all countries, however the actual magnitude of this increase in a specific country depends crucially on the strength of the spatial linkages and thus on the measurement of trade costs: i.e. the lower trade costs with Belgium, the larger the impact on a country’s gdp per capita.

Based on the estimation results from Table 8a and the various trade cost approximations, we have calculated the resulting gdp per capita changes as experienced by all other countries in response to the increased demand for their products from Belgium. Table 9 shows the correlation in gdp per capita effects for the different trade cost proxies and Figure 1 visualizes four of these correlations in some more detail.

Table 9 Correlations in response to a 5\% GDP shock in Belgium

\begin{tabular}{|c|c|c|c|c|c|c|c|c|}
\hline $\begin{array}{l}\text { Strategy } \\
\text {-Trade costs: }\end{array}$ & $\begin{array}{l}\text { 2step } \\
\text { - RV }\end{array}$ & $\begin{array}{l}\text { 2step } \\
\text { - Han }\end{array}$ & $\begin{array}{c}\text { 2step } \\
\text { - multipl. }\end{array}$ & $\begin{array}{l}\text { 2step } \\
\text { - add }\end{array}$ & $\begin{array}{l}\text { Direct } \\
- \text { RV }\end{array}$ & $\begin{array}{l}\text { direct } \\
\text { - Han }\end{array}$ & $\begin{array}{c}\text { direct } \\
\text { - multipl. }\end{array}$ & $\begin{array}{c}\text { direct } \\
-\varphi\end{array}$ \\
\hline $\begin{array}{l}\text { 2step } \\
\text { - RV }\end{array}$ & 1 & - & - & - & - & - & - & - \\
\hline $\begin{array}{l}\text { 2step } \\
- \text { Han }\end{array}$ & 0.423 & 1 & - & - & - & - & - & - \\
\hline $\begin{array}{l}\text { 2step } \\
\text { - multipl. }\end{array}$ & 0.983 & 0.490 & 1 & - & - & - & - & - \\
\hline $\begin{array}{l}2 \text { step } \\
- \text { add }\end{array}$ & 0.155 & 0.489 & 0.243 & 1 & - & - & - & - \\
\hline $\begin{array}{l}\text { direct } \\
-\mathrm{RV}\end{array}$ & 0.912 & $0.104 a$ & 0.880 & $0.068 a$ & 1 & - & - & - \\
\hline $\begin{array}{l}\text { direct } \\
- \text { Han }\end{array}$ & 0.825 & 0.422 & 0.825 & $0.149 a$ & 0.676 & 1 & - & - \\
\hline $\begin{array}{l}\text { direct } \\
\text { - Multipl. }\end{array}$ & 0.887 & $0.031 a$ & 0.852 & $0.021 a$ & 0.992 & 0.655 & 1 & \\
\hline $\begin{array}{l}\text { direct } \\
-\varphi\end{array}$ & 0.834 & 0.489 & 0.817 & $0.102 a$ & 0.700 & 0.671 & 0.684 & 1 \\
\hline
\end{tabular}

Note: - a - means not significant at the 5\% level 
Figure 1: Some correlations visualized
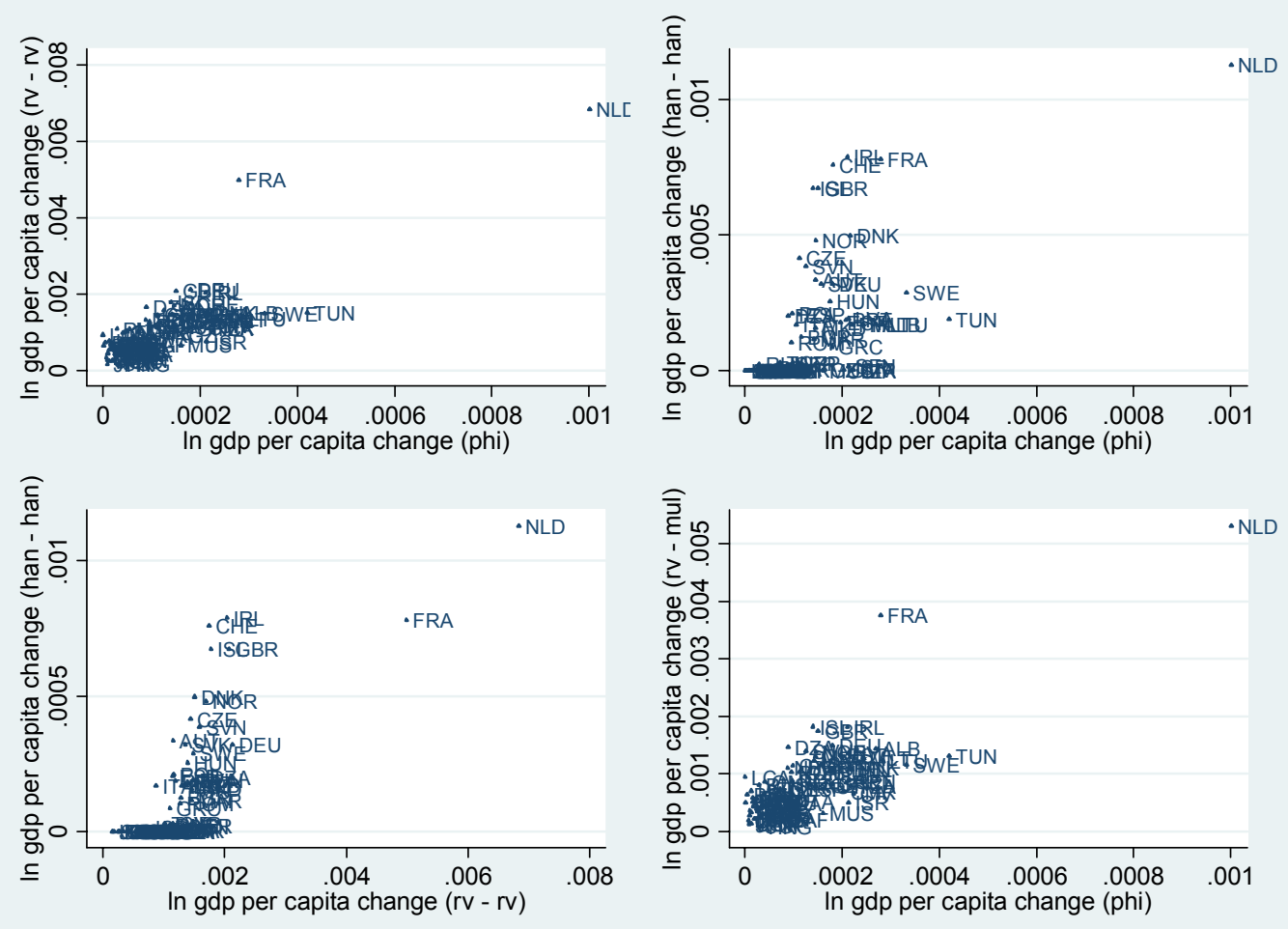

Notes: For the size of the correlations shown see Table 9.

As can be seen from Table 9, the correlation between the gdp per capita differs markedly across the various different trade cost proxies. For some proxies the correlation is quite high (especially between the "RV" and the "multiplicative" trade cost function), but also in some cases the correlation is rather low or even insignificant. No systematic difference in correlations between estimation strategies used can either be detected. Figure 1 complements this finding by plotting the different gdp per capita changes for four different trade cost specifications (i.e. Redding Venables (RV, with gdp in the trade cost function), Hanson (HAN), the multiplicative trade costs function (MULTPL) and the implied trade costs (PHI)) against each other. It illustrates in more detail that the spatial impact of a localized gdp shock differs quite a bit across trade cost specifications.

Figure 2 focusses explicitly on the spatial reach of the Belgian GDP shock. It plots the percentage gdp per capita change against log distance for the same four different trade cost approximations as shown in Figure 1: again the conclusions differ on the basis of the type of trade cost proxy used. 
Figure 2: $\quad$ gdp per capita changes, $5 \%$ gdp shock in Belgium and distance
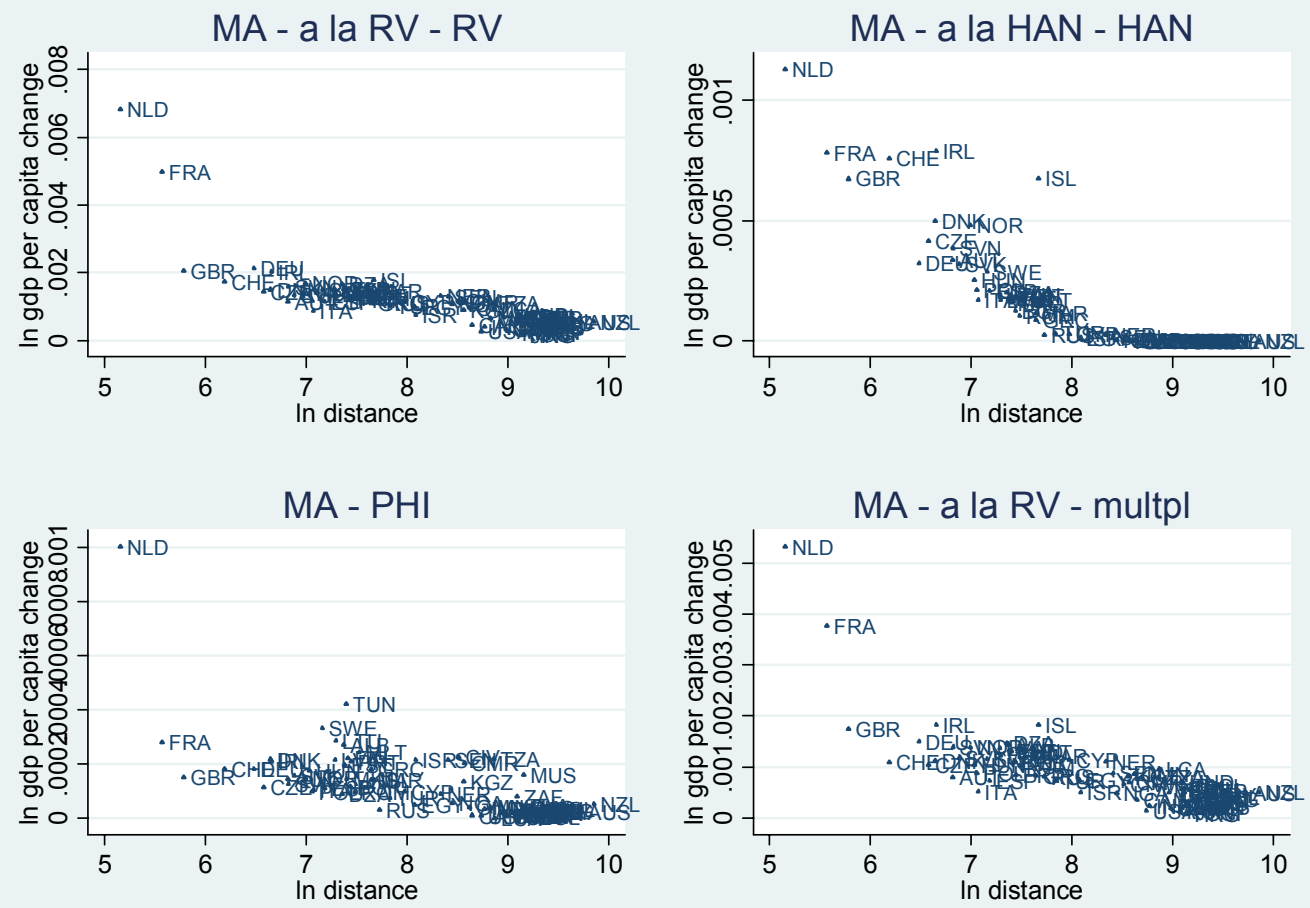

Notes: The correlation of the shock and ln distance are, going from upper left to lower right, $-0.77,-$ $0.84,-0.67,-0.76$ respectively.

In for instance the Hanson case (upper right panel) the distance decay is very strong and also the size of the gdp per capita changes is relatively small. Take for instance the case of the Netherlands (NLD). In the Redding and Venables specifications (upper left and lower right panels), the gdp per capita change is about 7 times as large as in the Hanson case. ${ }^{23}$ Figure 2 also shows that a more elaborate or heterogeneous trade costs specification (see the two lower panels) increases the variation of the gdp shock for countries at a similar distance to Belgium. Moreover this heterogeneity in differences in spatial reach corresponds predictively to the type of trade cost specification used.

When using the Hanson (2005) exponential trade cost function that depends solely on distance, the size and spatial reach of the Belgian income shock also depends heavily on distance. The correlation between the shock and log distance is the largest in this case. Moreover due to the exponential distance function used, the effect of the income shock quickly peters out; there is no discernable effect any more

\footnotetext{
${ }^{23}$ This seems to re-affirm the conclusion of Head and Mayer (2004, p. 2626) that the strong distance decay in Hanson (2005) " may be a consequence of the functional form of the distance decay function". See also Fingleton and McCann (2007).
} 
in countries lying farther from Belgium than Egypt (in the RV specification Egypt still experiences a $0.1 \%$ increase in gdp per capita; this is about the size of the wage increase in the most heavily affected country, the Netherlands, when using the Hanson specification).

The Redding and Venables (2004) specification also allows contiguity to have its effect on trade costs. Consequently the effect of the Belgian income shock, is less correlated with distance and has a larger effect on its contiguous neighbors. The shock now for example has a larger effect on Germany than on the closer (as measured by distance between capital cities) United Kingdom. Also the less extreme distance decay as implied by the estimated distance coefficient (compared to the exponential Hanson specification) ensures that the income shock peters out much slower and affects all countries in the sample in some way (Japan, with only a $0.02 \%$ increase in its gdp per capita, is affected the least).

All countries are also affected when allowing also for country specific trade cost factors in the multiplicative trade cost function. However, the correlation of the income shock with distance decreases somewhat further. Moreover the estimated positive (negative) effect of being an island (landlocked or a Sub-Saharan African country), has a clear effect on the effect of the Belgian income shock. Landlocked Switserland, and Sub-Saharan Côte d'Ivoire are relatively much less affected by the income shock for example, whereas island nations such as Ireland, New Zealand experience a relatively larger gdp per capita increase.

Finally when totally abstracting from the use of a trade cost function, by using implied trade costs, the effect of the Belgian income shock becomes even less correlated with distance. Given the way they are calculated the use of implied trade costs has the effect that countries that trade a lot with Belgium relative to the total amount of imports and exports between the two countries, such as Côte d'Ivoire, Finland or Sweden, experience a relatively larger impact of the Belgian income shock than countries that do not export/import a substantial amount of their total trade to Belgium but to other countries (e.g. Germany or Great Britain).

To sum up, from the evidence in Tables $8 \mathrm{a}, \mathrm{b}$ and 9 as well as in and Figures 1 and 2, we have to conclude that the way trade costs, a crucial elements of any NEG model, are approximated when doing empirical work has the potential to shape the overall conclusions about the empirical relevance of NEG and thus of the strength and the geographical reach of spatial interdependencies. The lesson for future NEG 
research is therefore that topic of trade costs should be given much more attention. Also the robustness of the results to the use of a particular trade cost proxy warrants more explicit attention.

\section{CONCLUSIONS}

Trade costs are a crucial element of new economic geography (NEG) models, without trade costs geography does not matter. The size of trade costs crucially determines the relevance of market access and thereby of inter-regional spatial interdependencies. The unavailability of actual trade costs data hampers empirical research in NEG and it requires the approximation of trade costs. Notwithstanding the importance of trade costs in NEG models, most empirical NEG studies do not pay attention to the ramifications of the particular trade costs specification used. This paper shows, both theoretically and empirically, that the way trade costs are specified matters. Estimations of a NEG wage equation for a sample of 80 countries shows that the relevance of the key NEG variable, market access, and hence of spatial interdependencies hinges nontrivially upon the trade costs specification. Using three estimation strategies and various trade cost specifications, the main conclusion is that NEG needs to (re-)examine the sensitivity of its empirical findings to the handling of trade costs.

New economic geography (NEG) is, of course, not the only theory around in spatial economics. But compared to urban and regional economics, NEG prides itself on the way it focuses on spatial interdependencies. These interdependencies come to the fore in the role market access and trade costs play in NEG whereas market access and trade costs are for instance typically neglected in urban economics (Combes, Duranton, and Overman, 2005, p. 320). Whether spatial interdependencies and hence market access and trade costs really matter is ultimately an empirical question. This paper argues that the answer to that, from an NEG perspective, crucial question can depend rather strongly on the empirical specification of trade costs. Future empirical research in NEG should therefore pay far more attention to the way trade costs are dealt with. Our paper provides a useful overview of the ex- and/or implicit assumptions made when approximating trade costs, hereby facilitating the choice of trade cost approximation when doing empirical work on NEG. 


\section{REFERENCES}

Anderson and van Wincoop, 2004, Trade Costs, Journal of Economics Literature, Vol.XLII, pp. 691-751.

Baier and Bergstrand, 2001, The growth of world trade: tariffs, transport costs, and income similarity, Journal of International Economics, Vol. 53, pp. 1-27.

Baldwin, R., R. Forslid, Ph. Martin, G.I.P. Ottaviano, and F. Robert-Nicoud, 2003, Economic Geography and Public Policy, Princeton University Press.

Brakman, S., H. Garretsen and M. Schramm, 2004, The Spatial Distribution of Wages: Estimating the Helpman-Hanson Model for Germany, Journal of Regional Science, 44(3), pp. 437-466.

Brakman, S. H. Garretsen and M. Schramm, 2006, Putting New Economic Geography to the Test, Regional Science and Urban Economics, 36(5), pp. 613-635.

Breinlich H., 2006, The spatial income structure in the European Union - what role for Economic Geography, Journal of Economic Geography, Vol. 6, pp. 593617.

Coe, D.T., A. Subramanian, N.T. Tamirisa and R. Bhavnani, The Missing Globalization Puzzle, IMF Working Paper, No. 02/171.

Combes, P-P. and H.G. Overman, 2004, The Spatial Distribution of Economic Activities in the EU, in V. Henderson and J-F. Thisse (eds.) The Handbook of Regional and Urban Economics, volume IV, North Holland, pp. 2845-2911.

Combes, P-P., G. Duranton and H. Overman, 2005, Agglomeration and the Adjustment of the Spatial Economy, Papers in Regional Science, 84(3), pp. 311-349.

Fingleton, B. and P. McCann, 2007, "Sinking the Iceberg? On the Treatment of Transport Costs in New Economic Geography”, in B. Fingleton (ed.), New Directions in Economic Geography, Edward Elgar, pp. 168-204.

Fujita, M., P. Krugman and A.J. Venables, 1999, The Spatial Economy, MIT Press.

Hanson, G., 2005, Market Potential, Increasing Returns and Geographic Concentration, Journal of International Economics, 67(1), pp.1-24.

Head, K and Th. Mayer, 2004, The Empirics of Agglomeration and Trade, in V. Henderson and J-F. Thisse (eds.) The Handbook of Regional and Urban Economics, volume IV, North Holland, pp.2609-2665.

Head, K. and Th. Mayer, 2006, Regional wage and employment responses to market potential in the EU, Regional Science and Urban Economics, 36(5), pp. 573594.

Head, K. and J. Ries, 2001, Increasing Returns versus National Product Differentiation as an Explanation for the Pattern of U.S. Canada Trade, American Economic Review, 91(4), pp. 858-876.

Helliwell J. and A-C Verdier, 2001, Measuring Internal Trade Distances: A New Method Applied to Estimate Provincial Border Effects in Canada, Canadian Journal of Economics, Vol. 34, pp. 1024-1041.

Hering and Poncet, 2006, Market Access impact on individual wages: evidence from China, working waper, CEPII

Hummels, D., 1999, Have international transportation costs declined?, manuscript, University of Chicago.

Hummels, D., 2001, Toward a Geography of Trade Costs, mimeo, Purdue University

Knaap. T., 2006, Trade, location, and wages in the United States, Regional Science and Urban Economics, 36(5), pp. 595-612.

Krugman, P., 1991, Increasing Returns and Economic Geography, Journal of Political Economy, nr. 3, 483-499. 
Krugman, P., 1995, Development, Geography and Economic Theory, MIT Press.

Limao and Venables, 2001, Infrastructure, Geographical Disadvantage, Transport Costs, and Trade, The World Bank Economic Review, Vol. 15, pp. 451-479.

McCann, P., 2001, A proof of the relationship between optimal vehicle size, haulage length and the structure of distance-transport costs, Transportation Research, 35A, pp.671 - 693 .

McCann, P., 2005, Transport costs and new economic geography, Journal of Economic Geography, Vol. 5, pp. 305 - 318.

Mion, G., 2004, Spatial Externalities and Empirical Analysis: The Case of Italy, Journal of Urban Economics, Vol. 56, pp. 97-118.

Puga, D. 1999. The rise and fall of regional inequalities, European Economic Review, Vol. 43, 303-334.

Redding, S. and A.J. Venables, 2004, Economic Geography and International Inequality, Journal of International Economics, 62(1), pp. 53-82.

Santos Silva and Tenreyro, 2006, The log of gravity, The Review of Economics and Statistics, Vol. 88, pp. 641-658.

Venables, A.J. 1996. Equilibrium Locations of Vertically Linked Industries, International Economic Review, 37, pp. 341-359.

\section{Appendix A}

\begin{tabular}{|c|c|c|c|}
\hline \multicolumn{4}{|c|}{ Countries included } \\
\hline Albania & Egypt & Latvia & Portugal \\
\hline Algeria & El Salvador & Lithuania & Romania \\
\hline Argentina & Estonia & Macau & Russia \\
\hline Armenia* & Ethiopia* & Macedonia & Saint Lucia \\
\hline Australia & Finland & Malawi* & Senegal \\
\hline Austria & France & Malaysia & Singapore \\
\hline Bahamas* & Germany & Malta & Slovakia \\
\hline Bangladesh* & Greece & Mauritius & Slovenia \\
\hline Barbados* & Guatemala* & Mexico & South Africa \\
\hline Belgium & Honduras & Moldova* & Spain \\
\hline Bolivia & Hong Kong & Mongolia & Sri Lanka* \\
\hline Brazil & Hungary & Morocco & Sweden \\
\hline Bulgaria & Iceland & Nepal* & Switzerland \\
\hline Cameroon & India & Netherlands & Taiwan \\
\hline Canada & Indonesia & New Zealand & Tanzania \\
\hline Cape Verde* & Ireland & Niger & Thailand \\
\hline Chile & Israel & Nigeria & Trinidad and Tobago* \\
\hline China & Italy & Norway & Tunisia \\
\hline Colombia & Japan & Oman & Turkey \\
\hline Costa Rica & Jordan* & Pakistan* & United Kingdom \\
\hline Côte d'Ivoire & Kenya* & Panama & United States of America \\
\hline Cyprus & Korea & Peru & Uruguay \\
\hline Czech Republic & Kuwait* & Philippines & Venezuela \\
\hline Denmark & Kyrgyzstan & Poland & Zimbabwe* \\
\hline Ecuador & & & \\
\hline
\end{tabular}

Note: * means the country is excluded in the wage equation estimation. 


\section{CESifo Working Paper Series}

for full list see www.cesifo-group.org/wp

(address: Poschingerstr. 5, 81679 Munich, Germany, office@cesifo.de)

2008 Mikael Priks, Judiciaries in Corrupt Societies, June 2007

2009 Steinar Holden and Fredrik Wulfsberg, Downward Nominal Wage Rigidity in the OECD, June 2007

2010 Emmanuel Dhyne, Catherine Fuss, Hashem Pesaran and Patrick Sevestre, Lumpy Price Adjustments: A Microeconometric Analysis, June 2007

2011 Paul Belleflamme and Eric Toulemonde, Negative Intra-Group Externalities in TwoSided Markets, June 2007

2012 Carlos Alós-Ferrer, Georg Kirchsteiger and Markus Walzl, On the Evolution of Market Institutions: The Platform Design Paradox, June 2007

2013 Axel Dreher and Martin Gassebner, Greasing the Wheels of Entrepreneurship? The Impact of Regulations and Corruption on Firm Entry, June 2007

2014 Dominique Demougin and Claude Fluet, Rules of Proof, Courts, and Incentives, June 2007

2015 Stefan Lachenmaier and Horst Rottmann, Effects of Innovation on Employment: A Dynamic Panel Analysis, June 2007

2016 Torsten Persson and Guido Tabellini, The Growth Effect of Democracy: Is it Heterogenous and how can it be Estimated?, June 2007

2017 Lorenz Blume, Jens Müller, Stefan Voigt and Carsten Wolf, The Economic Effects of Constitutions: Replicating - and Extending - Persson and Tabellini, June 2007

2018 Hartmut Egger and Gabriel Felbermayr, Endogenous Skill Formation and the Source Country Effects of International Labor Market Integration, June 2007

2019 Bruno Frey, Overprotected Politicians, June 2007

2020 Jan Thomas Martini, Rainer Niemann and Dirk Simons, Transfer Pricing or Formula Apportionment? Tax-Induced Distortions of Multinationals' Investment and Production Decisions, June 2007

2021 Andreas Bühn, Alexander Karmann and Friedrich Schneider, Size and Development of the Shadow Economy and of Do-it-yourself Activities in Germany, June 2007

2022 Michael Rauscher and Edward B. Barbier, Biodiversity and Geography, June 2007

2023 Gunther Schnabl, Exchange Rate Volatility and Growth in Emerging Europe and East Asia, June 2007 
2024 Erkki Koskela and Ronnie Schöb, Tax Progression under Collective Wage Bargaining and Individual Effort Determination, June 2007

2025 Jay Pil Choi and Marcel Thum, The Economics of Politically Connected Firms, June 2007

2026 Jukka Pirttilä and Roope Uusitalo, Leaky Bucket in the Real World: Estimating Inequality Aversion Using Survey Data, June 2007

2027 Ruslan Lukach, Peter M. Kort and Joseph Plasmans, Strategic R\&D with Knowledge Spillovers and Endogenous Time to Complete, June 2007

2028 Jarko Fidrmuc, Neil Foster and Johann Scharler, Labour Market Rigidities, Financial Integration and International Risk Sharing in the OECD, June 2007

2029 Bernardina Algieri and Thierry Bracke, Patterns of Current Account Adjustment Insights from Past Experience, June 2007

2030 Robert Dur and Hein Roelfsema, Social Exchange and Common Agency in Organizations, June 2007

2031 Alexander Libman and Lars P. Feld, Strategic Tax Collection and Fiscal Decentralisation: The Case of Russia, June 2007

2032 Øystein Foros, Hans Jarle Kind and Greg Shaffer, Resale Price Maintenance and Restrictions on Dominant Firm and Industry-Wide Adoption, June 2007

2033 Jan K. Brueckner and Kurt Van Dender, Atomistic Congestion Tolls at Concentrated Airports? Seeking a Unified View in the Internalization Debate, June 2007

2034 Viet Do and Ngo Van Long, International Outsourcing under Monopolistic Competition: Winners and Losers, June 2007

2035 Nadia Fiorino and Roberto Ricciuti, Determinants of Direct Democracy, June 2007

2036 Burkhard Heer and Alfred Maussner, Inflation and Output Dynamics in a Model with Labor Market Search and Capital Accumulation, June 2007

2037 Konstantinos Angelopoulos, Jim Malley and Apostolis Philippopoulos, Public Education Expenditure, Growth and Welfare, June 2007

2038 Maarten Bosker, Steven Brakman, Harry Garretsen and Marc Schramm, Adding Geography to the New Economic Geography, June 2007

2039 Steffen Henzel, Oliver Hülsewig, Eric Mayer and Timo Wollmershäuser, The Price Puzzle Revisited: Can the Cost Channel Explain a Rise in Inflation after a Monetary Policy Shock?, July 2007

2040 Rosario Crinò, Service Offshoring and White-Collar Employment, July 2007 
2041 Carsten Hefeker and Michael Neugart, Labor Market Regulation and the Legal System, July 2007

2042 Bart Cockx and Muriel Dejemeppe, Is the Notification of Monitoring a Threat to the Unemployed? A Regression Discontinuity Approach, July 2007

2043 Alfons J. Weichenrieder, Profit Shifting in the EU: Evidence from Germany, July 2007

2044 Annika Alexius and Bertil Holmlund, Monetary Policy and Swedish Unemployment Fluctuations, July 2007

2045 Axel Dreher, Jan-Egbert Sturm and Jakob de Haan, Does High Inflation Cause Central Bankers to Lose their Job? Evidence Based on a New Data Set, July 2007

2046 Guglielmo Maria Caporale and Luis A. Gil-Alana, Long Run and Cyclical Dynamics in the US Stock Market, July 2007

2047 Alessandro Balestrino, It is a Theft but not a Crime, July 2007

2048 Daniel Becker and Michael Rauscher, Fiscal Competition in Space and Time: An Endogenous-Growth Approach, July 2007

2049 Yannis M. Ioannides, Henry G. Overman, Esteban Rossi-Hansberg and Kurt Schmidheiny, The Effect of Information and Communication Technologies on Urban Structure, July 2007

2050 Hans-Werner Sinn, Please bring me the New York Times - On the European Roots of Richard Abel Musgrave, July 2007

2051 Gunther Schnabl and Christian Danne, A Role Model for China? Exchange Rate Flexibility and Monetary Policy in Japan, July 2007

2052 Joseph Plasmans, Jorge Fornero and Tomasz Michalak, A Microfounded Sectoral Model for Open Economies, July 2007

2053 Vesa Kanniainen and Panu Poutvaara, Imperfect Transmission of Tacit Knowledge and other Barriers to Entrepreneurship, July 2007

2054 Marko Koethenbuerger, Federal Tax-Transfer Policy and Intergovernmental PreCommitment, July 2007

2055 Hendrik Jürges and Kerstin Schneider, What Can Go Wrong Will Go Wrong: Birthday Effects and Early Tracking in the German School System, July 2007

2056 Bahram Pesaran and M. Hashem Pesaran, Modelling Volatilities and Conditional Correlations in Futures Markets with a Multivariate t Distribution, July 2007

2057 Walter H. Fisher and Christian Keuschnigg, Pension Reform and Labor Market Incentives, July 2007 
2058 Martin Altemeyer-Bartscher, Dirk T. G. Rübbelke and Eytan Sheshinski, Policies to Internalize Reciprocal International Spillovers, July 2007

2059 Kurt R. Brekke, Astrid L. Grasdal and Tor Helge Holmås, Regulation and Pricing of Pharmaceuticals: Reference Pricing or Price Cap Regulation?, July 2007

2060 Tigran Poghosyan and Jakob de Haan, Interest Rate Linkages in EMU Countries: A Rolling Threshold Vector Error-Correction Approach, July 2007

2061 Robert Dur and Klaas Staal, Local Public Good Provision, Municipal Consolidation, and National Transfers, July 2007

2062 Helge Berger and Anika Holler, What Determines Fiscal Policy? Evidence from German States, July 2007

2063 Ernesto Reuben and Arno Riedl, Public Goods Provision and Sanctioning in Privileged Groups, July 2007

2064 Jan Hanousek, Dana Hajkova and Randall K. Filer, A Rise by Any Other Name? Sensitivity of Growth Regressions to Data Source, July 2007

2065 Yin-Wong Cheung and Xing Wang Qian, Hoarding of International Reserves: Mrs Machlup's Wardrobe and the Joneses, July 2007

2066 Sheilagh Ogilvie, 'Whatever Is, Is Right'?, Economic Institutions in Pre-Industrial Europe (Tawney Lecture 2006), August 2007

2067 Floriana Cerniglia and Laura Pagani, The European Union and the Member States: Which Level of Government Should Do what? An Empirical Analysis of Europeans' Preferences, August 2007

2068 Alessandro Balestrino and Cinzia Ciardi, Social Norms, Cognitive Dissonance and the Timing of Marriage, August 2007

2069 Massimo Bordignon, Exit and Voice. Yardstick versus Fiscal Competition across Governments, August 2007

2070 Emily Blanchard and Gerald Willmann, Political Stasis or Protectionist Rut? Policy Mechanisms for Trade Reform in a Democracy, August 2007

2071 Maarten Bosker and Harry Garretsen, Trade Costs, Market Access and Economic Geography: Why the Empirical Specification of Trade Costs Matters, August 2007 